\title{
Developing scenarios of climate change for Southeastern Australia: an example using regional climate model output
}

\author{
P. H. Whetton*, J. J. Katzfey, K. J. Hennessy, X. Wu**, J. L. McGregor, K. Nguyen \\ CSIRO Atmospheric Research, PB No. 1, Aspendale, Victoria 3195, Australia
}

\begin{abstract}
Regional climate models nested in global climate models are now being used in Australia to produce high resolution climate change scenarios for use in impact assessments. This paper describes the development of such scenarios for the State of Victoria in Southeastern Australia using the CSIRO Division of Atmospheric Research Limited Area Model (DARLAM) at a horizontal resolution of $60 \mathrm{~km}$ nested in the slab ocean version of the CSIRO global climate model (GCM). Rainfall and temperature over Victoria are substantially better simulated in DARLAM than they are in the host GCM, although some poor features of the simulation of the seasonal cycle of rainfall have not been improved with the increase in resolution. There is evidence to suggest that some of these errors are due to errors in the simulation of atmospheric circulation provided by the host GCM. Under $2 \times \mathrm{CO}_{2}$ conditions, DARLAM simulates patterns of rainfall and temperature change which differ significantly from those provided by the host GCM and which appear more physically plausible. In particular, winter rainfall in southern Victoria increases in the DARLAM simulation, but decreases in the host GCM. Although the DARLAM scenario could be considered the best single scenario available for Victoria at the time of its production, it is noted that different, but equally plausible, scenarios could be obtained by nesting DARLAM in other GCMs, or by increasing the simulation sample size. Our assessment is that the rainfall changes simulated by DARLAM in summer may be most sensitive to such changes. In general, it is concluded that there is great potential to increase the realism of climate change scenarios in the Victorian region through careful use of nested regional modelling.
\end{abstract}

KEY WORDS: Climate change $\cdot$ Regional modelling $\cdot$ Scenarios $\cdot$ Australia

\section{INTRODUCTION}

Over the past decade CSIRO has been developing and issuing climate change scenarios for the Australian region (Pittock 1988, Whetton \& Pittock 1990, CSIRO 1992, 1996) which have seen widespread use in impact and policy studies (e.g., Brereton et al. 1995, Chiew et al. 1995, Sutherst et al. 1995, Whetton et al. 1996a, Schreider et al. 1997). The scenarios have been based on the regional results of global climate models (GCMs) and have been revised as new and more rele-

\footnotetext{
*E-mail: peter.whetton@dar.csiro.au

${ }^{* *}$ Present address: Antarctic Cooperative Research Centre and Australian Antarctic Division, GPO Box 252-80, Hobart, Tasmania 7001, Australia
}

vant modelling experiments have become available. An emphasis in this work has been on ensuring that current regional climate is adequately simulated by a GCM before it is used for scenario development (Whetton et al. 1994, 1996c), and on emphasising regional climate change features shared amongst a range of current GCMs and explicable physically (Whetton et al. 1996b).

A limitation with these GCM-based scenarios has been insufficient horizontal resolution. Although Australia is in general a continent of low relief, most of the population and most of the agricultural and economic activity is confined to the coastal regions in the east, southeast and southwest and their adjacent hinterland. These regions, and particularly those in the southeast, are topographically complex and contain marked cli- 
matic gradients and quite diverse climatic regimes. For such regions, GCMs (which typically have a horizontal resolution of between 200 and $500 \mathrm{~km}$ ) cannot reproduce many important details of the observed climate, nor can they simulate the strong spatial variations in climate change which may be expected. To address this deficiency, CSIRO has been developing a high resolution regional model which may be nested in a host GCM (McGregor \& Walsh 1994, Walsh \& McGre-
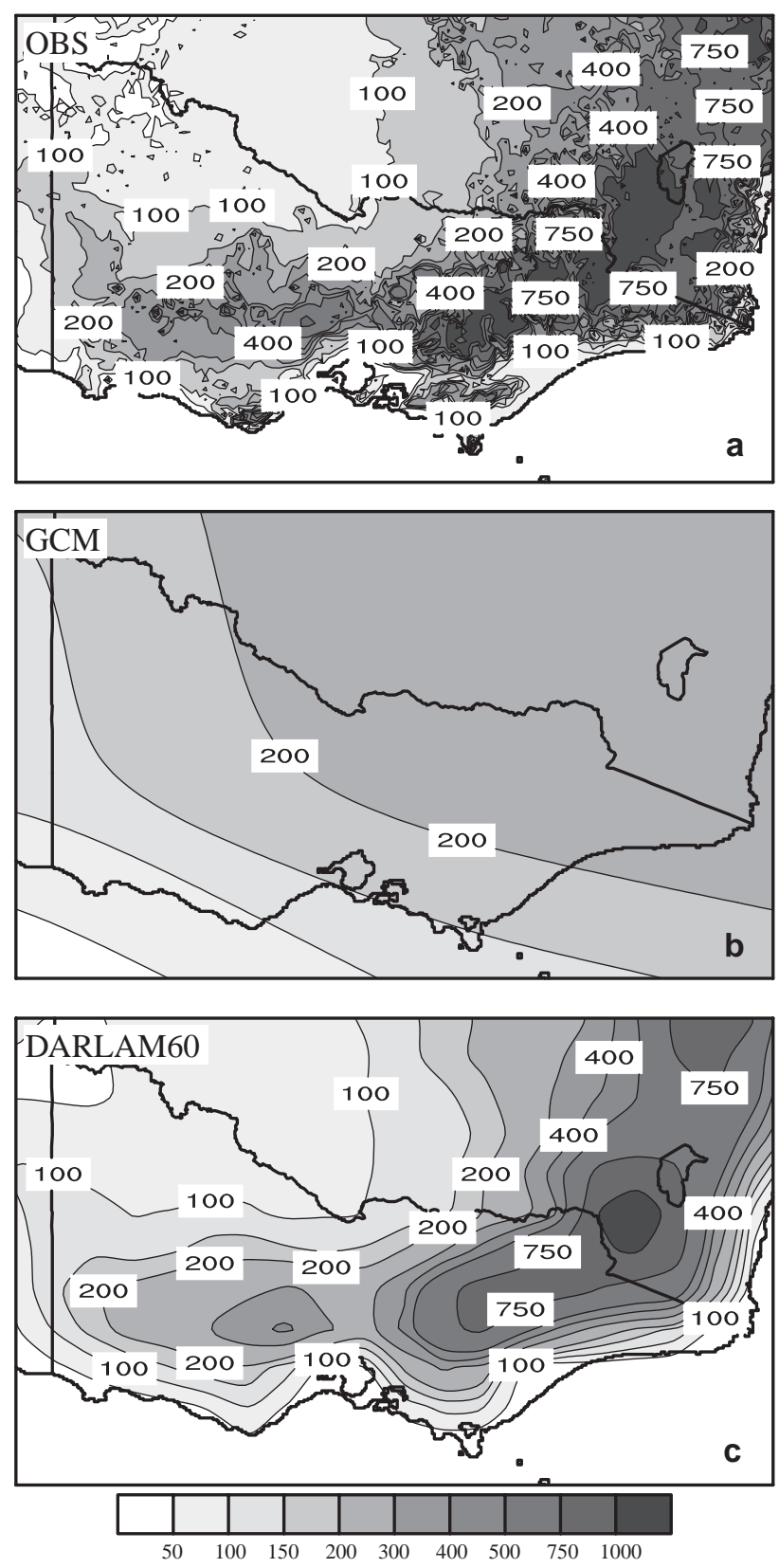

Fig. 1. Topography of the Victorian region: (a) as observed, (b) as represented in the CSIRO GCM, and (c) as represented in DARLAM at $60 \mathrm{~km}$ resolution. Units are metres gor 1995, McGregor 1997). The approach is very similar to that being pursued by a range of research centres throughout the world (e.g., Giorgi et al. 1994, 1998, Jones et al. 1997, Rotach et al. 1997). A recent review of issues associated with using regional models in climate studies is provided by Giorgi \& Mearns (1999).

The Australian regional modelling work has focussed on demonstrating the in-principle advantages of regional modelling rather than on providing high resolution climate change scenarios for use in impact studies. This is also true internationally, although there are some examples of the use of regional model scenarios in impact assessment. Mearns et al. $(1998,1999$ a) used regional model output of Giorgi et al. (1998) and demonstrated that crop yields over the Great Plains of the United States were sensitive to the spatial resolution of the scenarios used. Recently, there has been a growing demand amongst users of climate change information in Australia for the high resolution climate change information which is provided by regional models. Indeed, the governments of the States of Victoria and New South Wales contracted CSIRO to provide climate scenarios at a horizontal resolution of 60 $\mathrm{km}$ based on the results of simulations with the CSIRO regional climate model (Hennessy et al. 1997, Whetton et al. 1997, 2000a). The scenarios were then to be made available for use in impact assessment (e.g., Hassall \& Assoc 1998, Wang et al. 1999).

This paper outlines the scenarios of climate change that were prepared by CSIRO for the State of Victoria and considers a range of issues that arose in developing these scenarios and providing them to users. Although the benefits of higher resolution are very clear, the process of providing climate change scenarios to users based on nested regional modelling raises a number of issues that are not of concern, or of less concern, than when scenarios are based on a range of GCM results. Some of these are potentially of general interest and will be highlighted here.

Results will be presented here for maximum and minimum temperature and rainfall, but the majority of the discussion will focus on the rainfall results.

\section{OBSERVED RAINFALL IN THE VICTORIAN REGION}

Victoria lies between the latitudes of 35 and $40^{\circ} \mathrm{S}$ in the southeast corner of the Australian continent. Its limits are defined by the continental coastline in the south, the Murray River in the north, and arbitrary lines in the west and far east (Fig. 1a). The most significant physical feature of the State is the Great Dividing Range (hereafter referred to as 'the Divide') which runs from west to east across the centre of Victoria. 
This range is more extensive and higher in the east, with elevations typically between 1000 and $1500 \mathrm{~m}$. In the west of the State the elevation of the range is around $500 \mathrm{~m}$. In addition to the Divide, there are further ranges in the southernmost parts of the State. Victoria represents only $3 \%$ of Australia's total land area, but contains $25 \%$ of its total population.

Frontal systems imbedded in the westerlies are the most important rain-bearing source for the region, particularly in the winter months, June to August (JJA), when the westerlies are located in their most northerly position. The significance of these systems is evident in northern and western regions of the State, where there is a distinct winter maximum in the seasonal distribution of rainfall. Exposure to the west to southwesterly winds associated with fronts is greatest in the southwest of the State, where the winter maximum in rainfall is strongest.

The region north of the Divide differs from the southwest in that it is more exposed to tropical moisture advected to the region by northerly winds. Rainfall still peaks in this region in winter, but rain usually falls in the northwesterly winds ahead of fronts, often from cloud bands that have their origin over the tropical oceans to the northwest of Australia. Although not common, low pressure systems of tropical origin can bring heavy rainfall to northern Victoria in the summer months, December to February (DJF). In addition, northern Victoria is the region of the State where rainfall is most affected by variations in the El Niño-Southern Oscillation (ENSO) (Whetton 1988). The southeast quarter of the State has quite a different climate. Here exposure to westerly winds is much less, and more rain falls with east to southeasterly winds associated with low pressure systems off the southeast coast. These low pressure systems can be of tropical or midlatitude origin and can form at any time of the year. The seasonal rainfall distribution is uniform. For more discussion of rainfall patterns over Victoria see Whetton (1988).

\section{GCM-SIMULATED CHANGES IN RAINFALL IN THE VICTORIAN REGION}

Fig. 2 summarises simulated rainfall change in the Australian region in 13 different GCM enhanced greenhouse simulations. These simulations include 5 equilibrium $2 \times \mathrm{CO}_{2}$ experiments with slab ocean GCMs and 8 transient $\mathrm{CO}_{2}$ experiments with coupled ocean-atmosphere GCMs. Further details of the experiments are given in Table 1 . Note that the changes in rainfall given in Fig. 2 are expressed in terms of percentage rainfall change per ${ }^{\circ} \mathrm{C}$ of global warming. This means that model-to-model variations due to global climate sensitivity (magnitude of global warming for $2 \times \mathrm{CO}_{2}$ ) and enhanced greenhouse forcing are not included in the comparison.

There is a great deal of model-to-model variation in the results. Because of the relatively short averaging periods used (as little as $10 \mathrm{yr}$ in some cases, see Table 1), one would expect a good deal of variation simply due to natural climatic variability. However, a number of apparently systematic features emerge. In winter (JJA), there is clear zonal structure in the rainfall change patterns, with rainfall decreases in the subtropical band across the southern half of Australia and a predominance of rainfall increase over the ocean to the south. Victoria lies close to the boundary between these 2 regimes. This pattern is recognisable around the hemisphere, although the drying is more marked in the Australian longitudes (Whetton et al. 1996b). The rainfall increases polewards of $40^{\circ} \mathrm{S}$ occur in an oceanic zone with abundant rain-producing systems (the troughs in the midlatitude westerlies). In such an environment, increases in temperature may be expected to increase rainfall by enhancing evaporation. The decreases in rainfall under the southern hemisphere subtropical high pressure belt are less straightforward to understand and have yet to be the subject of systematic research. However this situation may be viewed as a consequence of a general strengthening of the hydrological cycle under enhanced greenhouse conditions, which leads to rainfall increases in the region of the ascending arm of the Hadley circulation (along the intertropical convergence zone) but decreases in the region of descent (primarily the southern subtropics in JJA). The greater intensity of the drying in Australian longitudes may relate to a tendency present in some of the simulations for greater warming in the eastern tropical Pacific and an associated El Niñolike pattern of rainfall change (Jones et al. 2000).

The GCM rainfall results in summer (DJF) are most striking over northwestern Australia, where there are large increases in the slab models and large decreases in the coupled models. The response of the Australian monsoon varies systematically between the coupled and slab experiments in a way which can be at least partly attributed to the different pattern of warming in these 2 types of experiments (Whetton et al. 1996b). This systematic difference in response is mostly absent in the southeast of continent, where simulated summer rainfall changes are small.

The GCM used in the current study for nesting the regional model is the CSIRO Mark 2 slab ocean GCM (Watterson et al. 1997). This was run for $30 \mathrm{yr}$ in the control $\left(1 \times \mathrm{CO}_{2}\right)$ and enhanced greenhouse $\left(2 \times \mathrm{CO}_{2}\right)$ experiments and the results of this GCM are represented by model 3 in Fig. 2. For the 2 regions in the southeast of the continent, the results from this GCM 
a

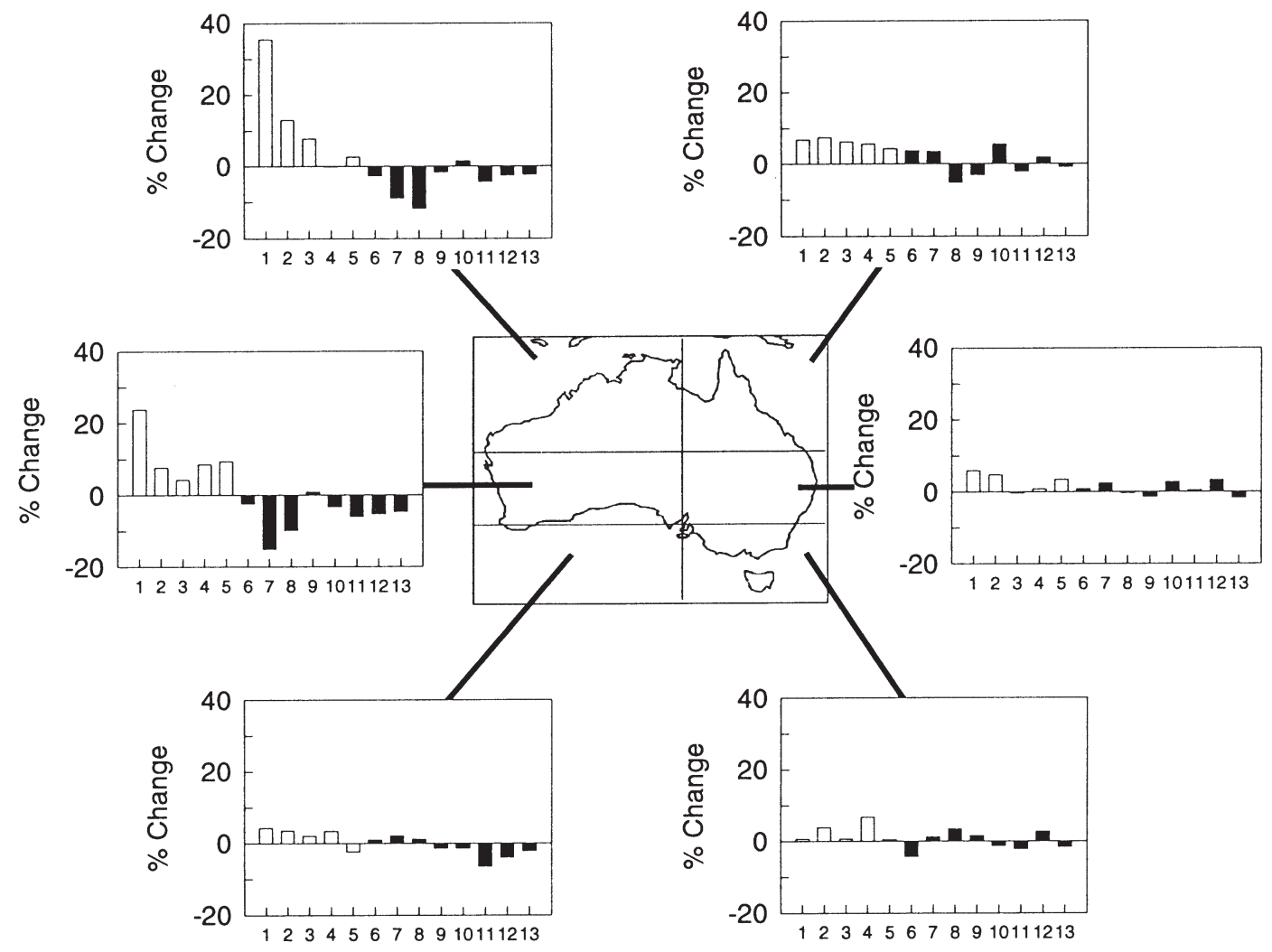

b

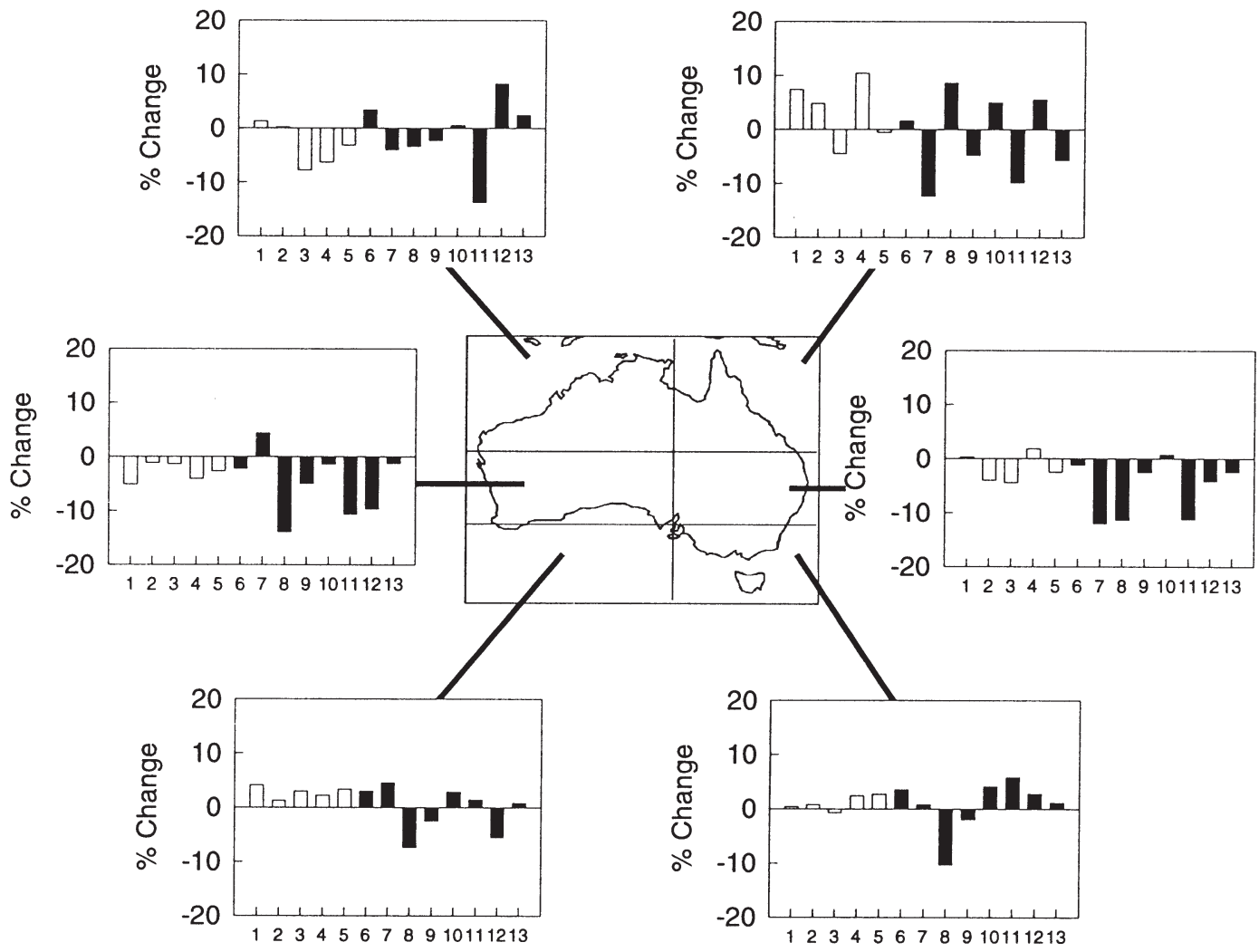

Fig. 2. Enhanced greenhouse regional rainfall changes (\% change per ${ }^{\circ} \mathrm{C}$ of global warming) for the GCM experiments listed in Table 1: (a) DJF (December to February) and (b) JJA (July to August). Simulations are numbered as in Table 1 
Table 1. Further details of the GCM experiments which provided the results used in Fig. 2. All experiments were forced with greenhouse gas increases only

\begin{tabular}{|lllll|}
\hline No. & Institution & \multicolumn{1}{c}{ Source } & Model type & $\begin{array}{c}\text { No. of years of data used for calculating } \\
\text { enhanced greenhouse changes }\end{array}$ \\
\hline 1 & BMRC & Colman et al. (1994) & Equil. slab ocean & 14 \\
2 & CCC & McFarlane et al. (1992) & Equil. slab ocean & 20 \\
3 & CSIRO & Watterson et al. (1997) & Equil. slab ocean & 30 \\
4 & GFDL & Houghton et al. (1990) & Equil. slab ocean & 10 \\
5 & Hadley Centre & Gregory \& Mitchell (1995) & Equil. slab ocean & 10 \\
6 & GFDL & Manabe et al. (1991) & Transient coupled & 10 \\
7 & DKRZ & Cubasch et al. (1992) & Transient coupled & 10 \\
8 & DKRZ & Lunkeit et al. (1994) & Transient coupled & 30 \\
9 & CCC & Boer et al. (in press) & Transient coupled & 30 \\
10 & GFDL & IPCC Data Distribution Centre & & 30 \\
11 & Hadley Centre & (http://ipcc-ddc.cru.uea.ac.uk) & Transient coupled & 30 \\
12 & DKRZ & ECHAM4hell \& Johns (1997) & Transient coupled & 30 \\
& & IPCC Data Distribution Centre & Transient coupled & 30 \\
\hline
\end{tabular}

are typical of the general model tendency (little rainfall change except in the more northerly of the 2 regions in winter, when there is a decrease). Note that, although Fig. 2 uses the full sample available from this model (30 yr), a 10 yr sample only was used for nesting the regional model, and subsequent figures in this paper in which the GCM and regional model results are compared use this $10 \mathrm{yr}$ sample from the GCM. Note also that as it is a slab ocean experiment the GCM simulation is not able to represent ENSO-related climatic variability.

\section{REGIONAL MODEL DETAILS}

High resolution climate simulations for Victoria were produced using the Division of Atmospheric Research Limited Area Model (DARLAM) (McGregor 1997) nested within the CSIRO GCM described above. A horizontal resolution of $60 \mathrm{~km}$ is achieved through a double nested technique. Firstly, DARLAM was nested in the GCM using $125 \mathrm{~km}$ resolution over Australasia. This provided fine resolution boundary conditions for a second nesting over southeastern Australia at $60 \mathrm{~km}$ resolution. Ten years of $1 \times \mathrm{CO}_{2}$ and $10 \mathrm{yr}$ of $2 \times \mathrm{CO}_{2}$ conditions were simulated with the nested model over the full annual cycle. Fig. 1 shows the topography of the GCM and of DARLAM at $60 \mathrm{~km}$ resolution over Victoria. It is notable that the climatically important Divide, which is absent in the GCM, is well represented at $60 \mathrm{~km}$ resolution.
The physical parameterisations and dynamical framework of DARLAM are detailed in McGregor (1994, 1997). The maximum and minimum temperature fields discussed here are computed for $2 \mathrm{~m}$ above the surface. An experiment with DARLAM nested in ECMWF (European Centre for Medium Range Weather Forecasting) analyses indicated a surface temperature bias of over $1^{\circ} \mathrm{C}$ in the Australian region (Katzfey 1993).

\section{SIMULATION OF CURRENT CLIMATE}

In this section the patterns of seasonal mean daily maximum temperature, daily minimum temperature and rainfall over Victoria, as simulated in DARLAM for control conditions, are presented. These are compared with the corresponding patterns simulated by the host GCM (based on the same simulation period used for nesting DARLAM) and the corresponding observed patterns.

In addition, some statistical measures of model performance are presented. Three statistics are used: the difference between the spatial means of the model and the observed fields ('bias'); pattern correlation; and the ratio of the spatial variance of the model to that as observed (' $V_{\mathrm{m}} / V_{\mathrm{o}}$ '). Similar statistics were used by Giorgi et al. (1994). The bias indicates whether the model results are generally too high, or too low, relative to the observations. The pattern correlation is a measure of the similarity of the spatial patterns of the model results and the observations. The ratio of vari- 
ances compares the amplitudes of the observed and modelled patterns (e.g., it tests whether the magnitudes of the maxima and minima are correct). Values less than 1 indicate that the amplitude of the modelled spatial pattern is too weak (e.g., minima not low enough and maxima not high enough relative to the mean), whereas values greater than 1 indicate that the modelled pattern is too intense.

The gridded observed monthly temperature and rainfall climatologies used for model validation are based on averages of data for all years of record at each of the Australian Bureau of Meteorology climate stations. This data set is summarised in Bureau of Meteorology (1988), although the data set used here was updated to around 1990. About 200 climate stations contribute to the climatologies in our study

\section{DJF}
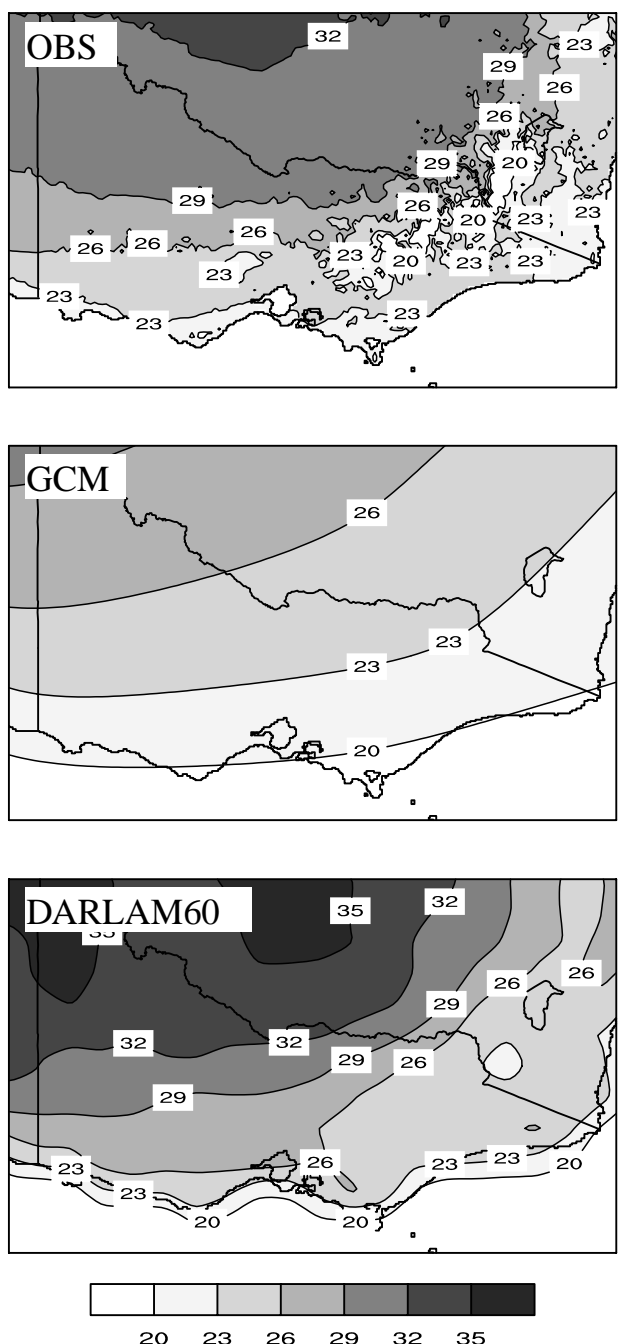

region. Although data from earlier years were used, consideration of variations in station density indicates that the climatologies predominantly represent the post-1950 period. Such a data set can be considered to adequately sample regional climatic variability associated with the ENSO. The data were interpolated to a grid with a resolution of $1 / 16^{\circ}$ (around $7 \mathrm{~km}$ ) using a method that takes into account the dependence of climate on elevation (Hutchinson \& Bischoff 1983). This method uses a cubic spline surface to represent the dependence of the climate variable on latitude, longitude, elevation and time (month). Use of an elevationdependent interpolation helped to compensate for potential biases due to the non-uniform distribution of stations (such as a tendency for stations to be more common in valleys than on mountains). For the calcu-

\section{JJA}
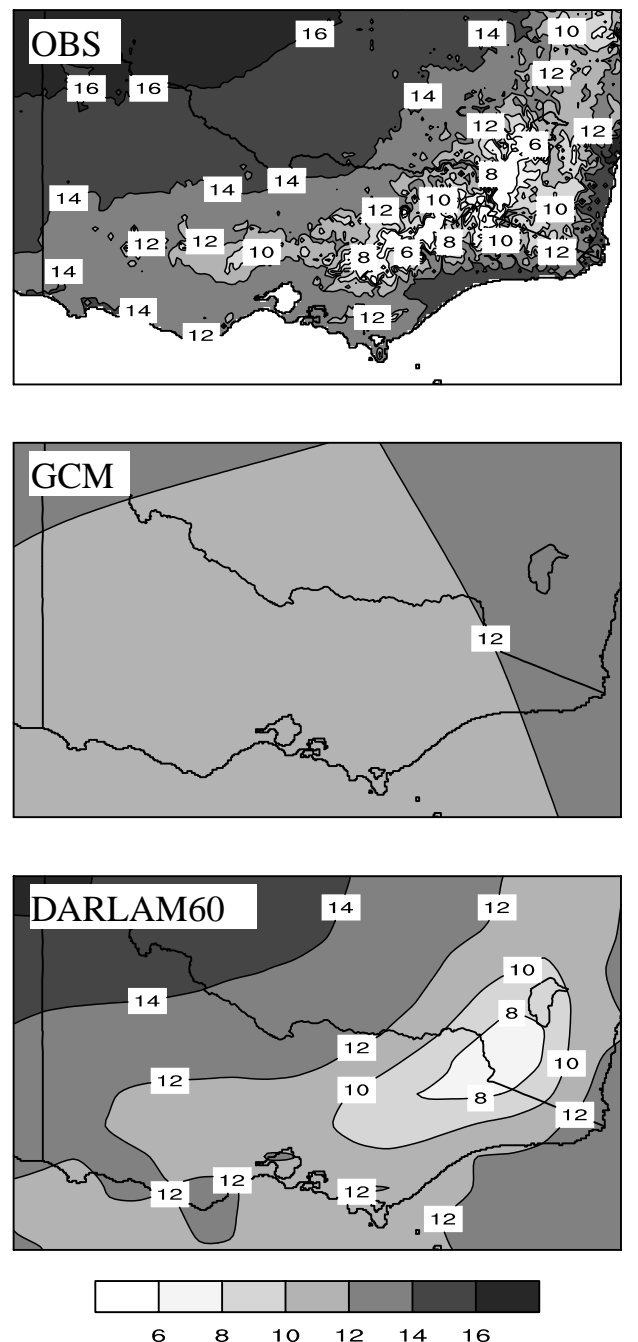

Fig. 3. Mean seasonal daily maximum temperature as observed ('OBS') and as simulated by the GCM and DARLAM. Units are ${ }^{\circ} \mathrm{C}$ 
lation of the validation statistics, DARLAM and GCM fields were also interpolated to this $1 / 16^{\circ}$ grid (although in this case elevation dependence was not included). Because the observed data were for land only, but model data were for both land and sea, use of a fine grid for comparing the model and observations minimised the loss of observed climate information in coastal regions relevant to validating the models.

\subsection{Daily maximum temperature}

Fig. 3 shows maps of daily maximum temperature over Victoria as observed and as simulated by the GCM and DARLAM for the summer (DJF) and winter (JJA) months. Table 2 gives validation statistics for all 4 seasons for the land area of the domain used in Fig. 3. Daily maximum temperatures were significantly too low in the GCM throughout the year, with a regional bias ranging from $-3.5^{\circ} \mathrm{C}$ in summer to $-1.6^{\circ} \mathrm{C}$ in winter. This tendency has been largely removed in DARLAM, although a bias of $+2.0^{\circ} \mathrm{C}$ occurs in summer. This improvement may be partially attributed to an inherent positive temperature bias in DARLAM (Katzfey 1993). The structure and amplitude of the spatial pattern of maximum temperature is quite realistic in DARLAM where it was not in the GCM. The observed pattern of maximum temperature can be viewed as a combination of 2 effects: a northward increase in temperature (which is most marked in summer when it is accentuated by the land-sea temperature contrast) and the decrease in temperature with elevation which leads to a temperature minimum over the mountains in the east (particularly in winter, when the first effect is weaker). Both models capture the first of these effects, although the GCM amplitude is too weak. As may be expected, only DARLAM captures the second effect.

Table 2. Validation statistics for simulation of daily maximum temperature over the Victorian region for DARLAM and the GCM. The statistics used are the following: the difference between the spatial means of the model and the observed fields ('bias'); pattern correlation ('corr.'); and the ratio of the spatial variance of the model to that as observed (' $V_{\mathrm{m}} / V_{\mathrm{o}}$ '). Bold type indicates which of the corresponding values from GCM and DARLAM are closest to the ideal values. Calculations were made for the land area of the domain used in Fig. 2. DJF: December to February, MAM: March to May, JJA: June to August; SON: September to November

\begin{tabular}{|lrrrrrr|}
\hline \multirow{2}{*}{ Season } & \multicolumn{2}{c}{ GCM } & \multicolumn{3}{c|}{ DARLAM } \\
& Bias $\left({ }^{\circ} \mathrm{C}\right)$ & Corr. & $V_{\mathrm{m}} / V_{\mathrm{o}}$ & Bias $\left({ }^{\circ} \mathrm{C}\right)$ & Corr. & $V_{\mathrm{m}} / V_{\mathrm{o}}$ \\
\hline DJF & -3.51 & 0.92 & 0.67 & $\mathbf{1 . 9 5}$ & $\mathbf{0 . 9 3}$ & $\mathbf{1 . 1 0}$ \\
MAM & -2.28 & 0.75 & 0.50 & $\mathbf{0 . 4 4}$ & $\mathbf{0 . 9 4}$ & $\mathbf{1 . 1 2}$ \\
JJA & -1.57 & -0.07 & 0.22 & $\mathbf{- 1 . 0 4}$ & $\mathbf{0 . 9 5}$ & $\mathbf{0 . 8 2}$ \\
SON & -2.14 & 0.83 & 0.59 & $\mathbf{0 . 2 1}$ & $\mathbf{0 . 9 4}$ & $\mathbf{0 . 9 4}$ \\
\hline
\end{tabular}

\subsection{Daily minimum temperature}

Fig. 4 shows seasonal maps of daily minimum temperature over Victoria as observed, and as simulated by DARLAM and the GCM. Table 3 gives corresponding seasonal validation statistics. Regionally averaged daily minimum temperature is considerably better simulated in DARLAM than it is in the GCM. The average of this field is 1.5 to $2.0^{\circ} \mathrm{C}$ too high in the GCM, whereas in DARLAM it is within $0.3^{\circ} \mathrm{C}$ of that observed (see bias results in Table 3). If this result is considered in conjunction with the bias results for maximum temperature, it is seen that the diurnal range in temperature is very much better simulated in DARLAM than in the GCM (Table 4). Diurnal range is 3.5 to $5.0^{\circ} \mathrm{C}$ too small in the GCM, whereas it is much closer to the observed range in DARLAM. There is a very marked improvement in the simulation of the spatial pattern of minimum temperature in DARLAM compared to the GCM. Indeed, the pattern correlation statistic is markedly superior in all seasons (Table 3). DARLAM reproduces the observed tendency for minimum temperatures to be least over the mountains of the northeast and higher in coastal areas and in the far north (Fig. 4). The GCM shows a broad tendency, in all seasons but DJF, for minimum temperatures to increase towards the coast, but otherwise the GCM patterns are not realistic. It is interesting to note that some subtle features of the seasonal cycle are captured in DARLAM. An example is the tendency for the region of lowest minimum temperatures in central and western Victoria to lie nearer the coast in DJF compared to JJA. The range in temperature across

Table 3. Validation statistics for simulation of daily minimum temperature over the Victorian region for DARLAM and the GCM. See Table 2 for further details

\begin{tabular}{|lrrrrrr|}
\hline \multirow{2}{*}{$\begin{array}{l}\text { Season } \\
\end{array}$} & \multirow{2}{*}{ GCM } & \multicolumn{4}{c|}{ DARLAM } \\
& Bias $\left({ }^{\circ} \mathrm{C}\right)$ & Corr. & $V_{\mathrm{m}} / V_{\mathrm{o}}$ & Bias $\left({ }^{\circ} \mathrm{C}\right)$ & Corr. & $V_{\mathrm{m}} / V_{\mathrm{o}}$ \\
\hline DJF & 1.56 & 0.10 & 0.59 & $\mathbf{0 . 2 3}$ & $\mathbf{0 . 9 3}$ & $\mathbf{1 . 1 9}$ \\
MAM & 1.89 & -0.32 & 0.79 & $\mathbf{- 0 . 2 0}$ & $\mathbf{0 . 9 0}$ & $\mathbf{1 . 0 3}$ \\
JJA & 2.01 & -0.17 & $\mathbf{0 . 8 7}$ & $\mathbf{0 . 2 2}$ & $\mathbf{0 . 9 0}$ & 0.74 \\
SON & 1.90 & -0.34 & 0.70 & $\mathbf{0 . 3 1}$ & $\mathbf{0 . 9 1}$ & $\mathbf{1 . 0 4}$ \\
& & & & & & \\
\hline
\end{tabular}

Table 4. Bias in regionally averaged diurnal range of temperature as simulated in the GCM and DARLAM. Units are in ${ }^{\circ} \mathrm{C}$. Bold as in Tables $2 \& 3$

\begin{tabular}{|lcc|}
\hline Season & GCM & DARLAM \\
\hline DJF & -5.07 & $\mathbf{1 . 7 2}$ \\
MAM & -4.17 & $\mathbf{0 . 6 4}$ \\
JJA & -3.58 & $\mathbf{- 1 . 2 6}$ \\
SON & -4.04 & $\mathbf{- 0 . 1 1}$ \\
\hline
\end{tabular}


DJF
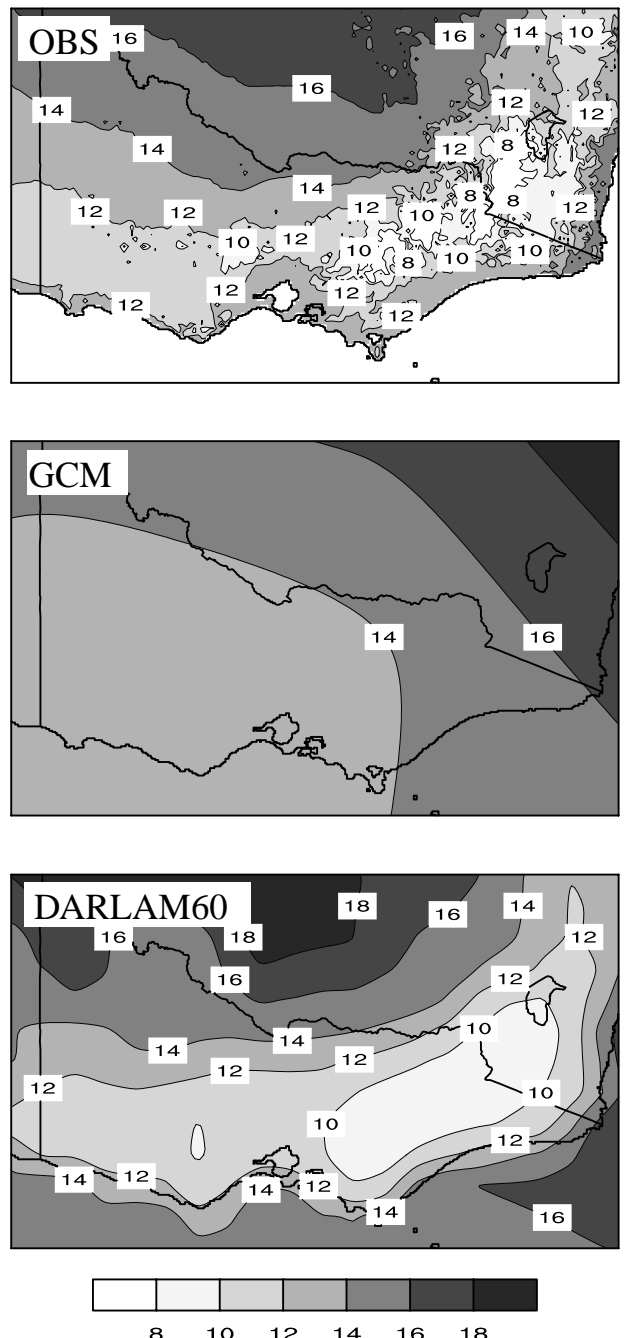

JJA
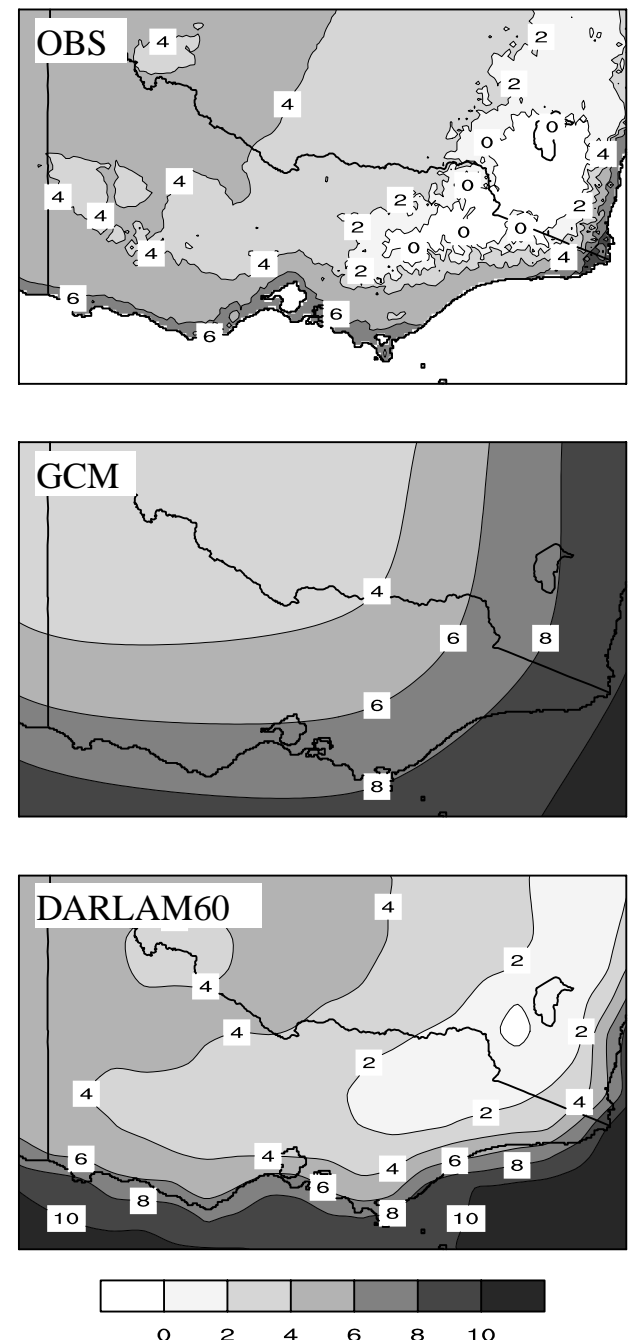

Fig. 4. Mean seasonal daily minimum temperature as observed ('OBS') and as simulated by the GCM and DARLAM. Units are ${ }^{\circ} \mathrm{C}$

the State has been increased in DARLAM and now matches the observations better (this is reflected in the $V_{\mathrm{m}} / V_{\mathrm{o}}$ statistics in Table 3$)$.

Table 5. Validation statistics for simulation of rainfall over the Victorian region for DARLAM and the GCM. See Table 2 for further details

\begin{tabular}{|lrcrrrr|}
\hline Season & \multicolumn{3}{c}{ GCM } & \multicolumn{3}{c|}{ DARLAM } \\
& $\begin{array}{l}\text { Bias } \\
\left(\mathrm{mm} \mathrm{d}^{-1}\right)\end{array}$ & Corr. & $V_{\mathrm{m}} / V_{\mathrm{o}}$ & \multicolumn{2}{c}{$\begin{array}{c}\text { Bias } \\
\left(\mathrm{mm} \mathrm{d}^{-1}\right)\end{array}$} \\
& & & & & \\
\hline DJF & $\mathbf{0 . 5 1}$ & 0.49 & $\mathbf{0 . 6 4}$ & 0.91 & $\mathbf{0 . 8 2}$ & 2.17 \\
MAM & $\mathbf{- 0 . 4 2}$ & 0.60 & 0.72 & -0.50 & $\mathbf{0 . 7 6}$ & $\mathbf{0 . 8 5}$ \\
JJA & -0.72 & 0.39 & $\mathbf{0 . 5 5}$ & $\mathbf{- 0 . 5 1}$ & $\mathbf{0 . 9 0}$ & 0.45 \\
SON & -0.32 & 0.64 & 0.24 & $\mathbf{0 . 1 8}$ & $\mathbf{0 . 8 3}$ & $\mathbf{0 . 8 2}$ \\
& & & & & & \\
\hline
\end{tabular}

\subsection{Rainfall}

Fig. 5 shows seasonal maps of rainfall over Victoria as observed and as simulated by the GCM and DARLAM. Table 5 gives the corresponding seasonal validation statistics.

Although the spatial correlations are not as high as they are for temperature, it is still evident that the spatial pattern of rainfall is very much improved in DARLAM compared to the GCM (see pattern correlation values in Table 5). In broad terms, the pattern of observed rainfall over Victoria is a combination of a tendency for greater rainfall in the south compared to the north (the effect of proximity to the sea) and a tendency of greater rainfall over the ranges in eastern Victoria compared to elsewhere (the effect of mountains 
enhancing rainfall). Both these tendencies are clearly evident in the DARLAM results, but largely absent in the GCM, although the coastal effect is evident in JJA (Fig. 5).

However, errors in regionally averaged rainfall are similar in DARLAM to those in the GCM (see bias in Table 5), and the simulation of the seasonal cycle of regional rainfall is not much improved over that provided by the GCM. This was examined further using an analysis based on the 6 subregions defined in Fig. 6. Fig. 7 shows observed and simulated (DARLAM and GCM) average monthly rainfall for each of these subregions (calculated after interpolation to the $1 / 16^{\circ}$ grid used by the observations) and corresponding correlation coefficients. The analysis shows that observed rainfall is generally highest in winter or early spring and lowest in summer. This pattern is more evident over the western two-thirds of the domain and most evident in the southwest subregion. The GCM simulates a winter-spring maximum in rainfall only in the southwest subregion. Elsewhere, simulated rainfall has an unrealistic tendency to peak in summer, except in the southeastern subregion, where the GCM gives, in reasonable agreement with observations, a uniform seasonal rainfall distribution. Over the western two-thirds of the region, the DARLAM simulation is slightly improved in comparison with the GCM results. A tendency toward a summer rainfall maximum remains only in the northern subregion. However, in the eastern third of the domain (the southeast and northeast subregions), DARLAM simulates a regime in which summer rain-

\section{DJF}
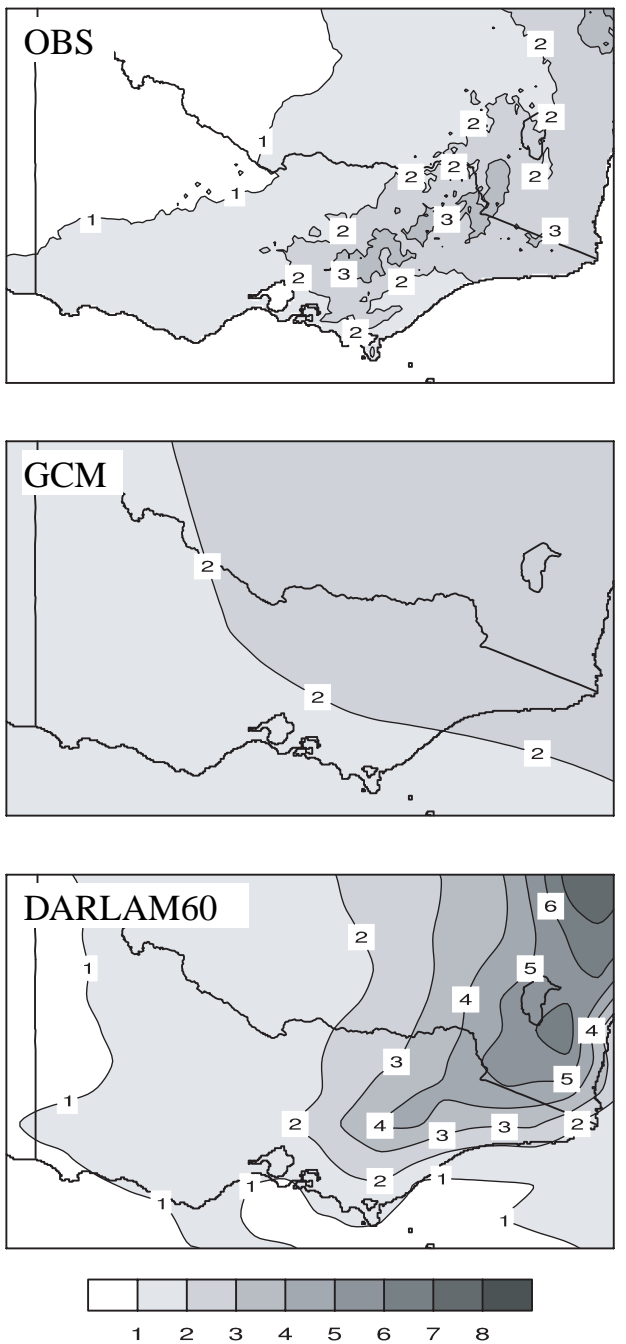

JJA
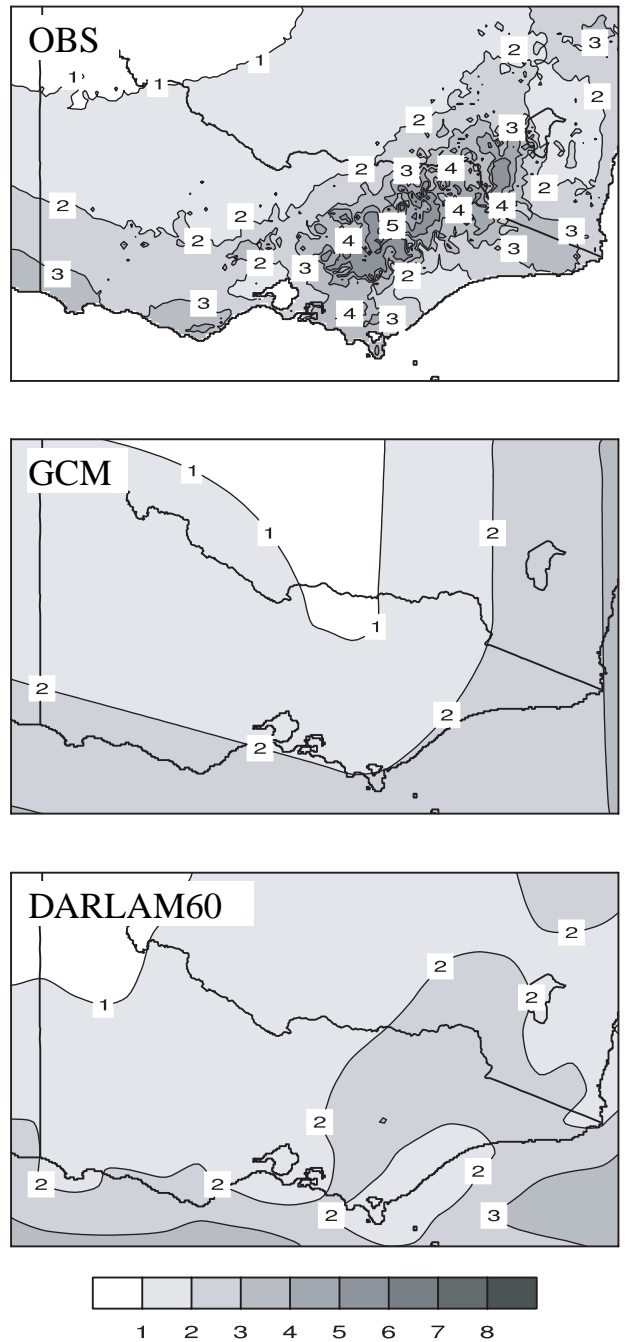

Fig. 5. Mean seasonal rainfall as observed ('OBS') and as simulated by the GCM and DARLAM. Units are $\mathrm{mm} \mathrm{d}^{-1}$ 


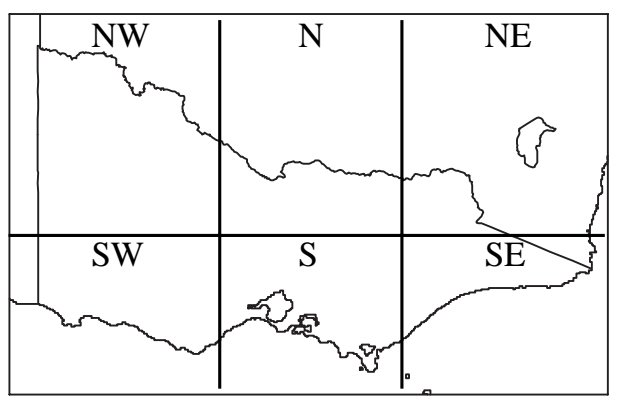

Fig. 6. Division of Victoria into the 6 subregions used for calculating the results presented in Fig. 7 . Reference in the text will be to the 'northwest' (NW), 'northern' (N), 'northeast' (NE), 'southeast' (SE), 'southern' (S), and 'southwest' (SW) subregions

fall is strongly dominant. This compares poorly with the observations and with the GCM simulation. This feature stems from the unrealistic marked peak in rainfall (over $4 \mathrm{~mm} \mathrm{~d}^{-1}$ ) which is simulated over the mountains in the far east of the domain.

In summary it appears that increased resolution has led to an increase in the realism of the spatial pattern of rainfall simulation over Victoria. However, it also appears that there are significant errors in the seasonal cycle of regional averaged rainfall which have not been ameliorated by increased resolution. In particular, the tendency for the GCM rainfall to be too low in winter has persisted in the DARLAM simulation. Further, DARLAM has introduced an unwanted tendency for high summer rainfall over the mountains in the east of the State.

\section{ATMOSPHERIC CIRCULATION}

The tendency for broad-scale errors in rainfall to not improve as resolution is increased suggests that the source of this problem lies elsewhere. A possibility is that DARLAM is simulating rainfall occurrence based on broad-scale atmospheric circulation patterns provided by the GCM which are in error. Simulation errors in the host GCM have been cited as an important source of regional model bias in European studies (Machenhauer et al. 1996). This possibility is investigated here by comparing errors in the DARLAM-simulated seasonal rainfall with the corresponding errors in the simulation of mean sea level pressure (MSLP). The reference climatology for MSLP was that of Karoly et al. (1987) for the period 1972-1982 and the rainfall data set was constructed from station data for the same period.

Fig. 8a \& b show observed and GCM-simulated MSLP for JJA, and Fig. 8c shows the differences between these two (the 'errors'). The dominant feature of the observed and simulated patterns over southern Australia is the strong westerly flow represented by the steep poleward decrease in pressure. An important, but much more subtle, feature is the tendency for pressure to be lower over and south of western Australia than it is at the same longitudes in eastern Australia. The GCM is able to reproduce this 'Western Australian trough', but in the model it is too weak (hence the pressure errors in the region of +1 to $+5 \mathrm{hPa}$ seen in Fig. 8c). The errors in MSLP flow through to the MSLP simulation of DARLAM largely unmodified (Fig. 9a), with the consequence that pressure is too high over Victoria and the error increases southwestwards from the State. This pattern would lead to a weakening of the prevailing west to northwesterly winds in winter, and as these winds are an important source of rainfall for Victoria in this season, lower rainfall would be expected. Rainfall is indeed simulated to be lower than observed (Fig. 9b). The magnitude of pressure errors (1 to $2.5 \mathrm{hPa}$ ) are large enough in a seasonal mean to have a significant impact on rainfall (see the results in general of Whetton 1986). In other seasons, GCM-simulated MSLP patterns are reproduced with little change in DARLAM. An MSLP error similar to that seen in winter may explain, in qualitative terms, the depressed rainfall of autumn (March to May, MAM), whereas the absence of such a MSLP error can explain the greater accuracy of the spring (September to November, SON) rainfall simulation (results not shown).

Similar analysis (not shown) was undertaken to assess whether broad-scale MSLP errors may explain the tendency for summer rainfall to be too high in northeastern Victoria. However, in this case the pressure errors were small and the rainfall errors were much more evident in DARLAM than in the host GCM. A problem of too much rainfall over orography is quite common in regional modelling studies, but a single cause of this problem has not been identified. Authors have cited the tendency of models to simulate too many rain days, especially light events (Marinucci et al. 1995, Mearns et al. 1995, Renwick et al. 1998), a tendency for diffusion of moisture up slopes to be too strong (Christensen et al. 1997) and deficiencies in the simulation of convection (Marinucci et al. 1995), and there can be difficulties in accurately calculating pressure gradient terms near orography. Sometimes the model can underpredict intensity, which can offset the overprediction of frequency, resulting in nearly correct mean rainfall (Mearns et al. 1995). It has also been suggested that the paucity of observations at high elevation may cause the observed climatologies to be biased too low (Marinucci et al. 1995, Christensen et al. 1997). Development of a subgrid-scale 
GCM
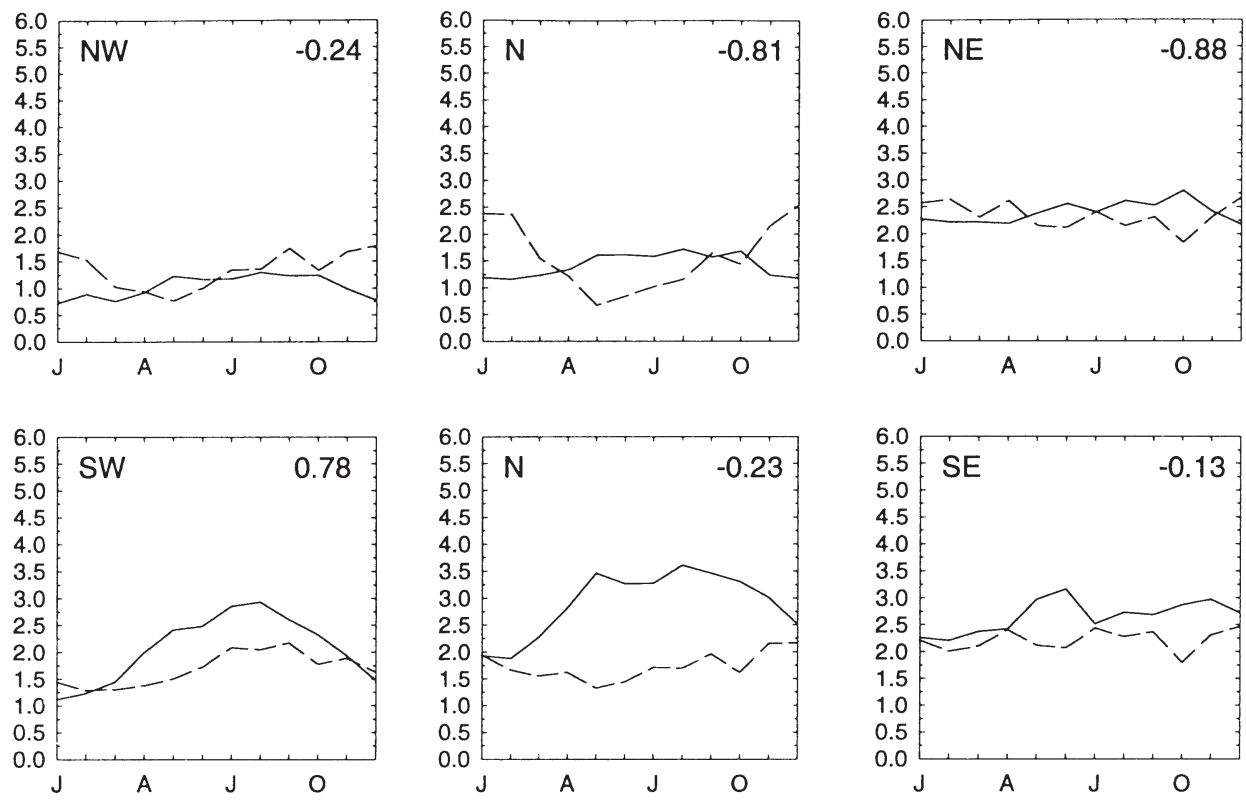

\section{DARLAM60}
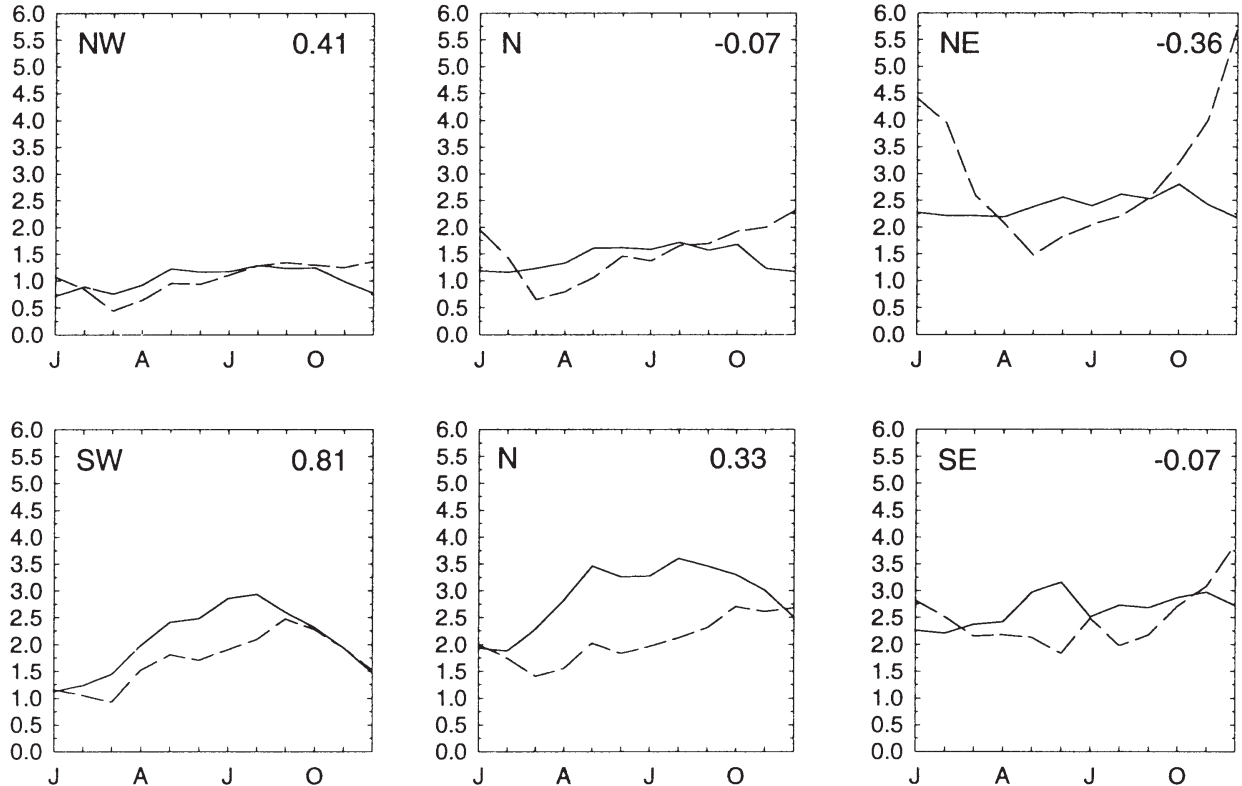

Fig. 7. Seasonal cycle of rainfall for the subregions defined in Fig. 6 as observed (solid line) and simulated (dashed line). The upper frames give the GCM results and the lower frames the DARLAM results. Units are $\mathrm{mm} \mathrm{d}^{-1}$. Correlation coefficients are given in the top right of each panel

parameterisation of orography (Leung \& Ghan 1995) has led to a marked improvement in the simulation of orographic precipitation. Addressing this issue will be a focus of ongoing model development work with DARLAM.

\subsection{Summary of DARLAM performance}

In general, the climate of the Victorian region is much better simulated in DARLAM than in the host GCM. The improvements are most marked in the representa- 

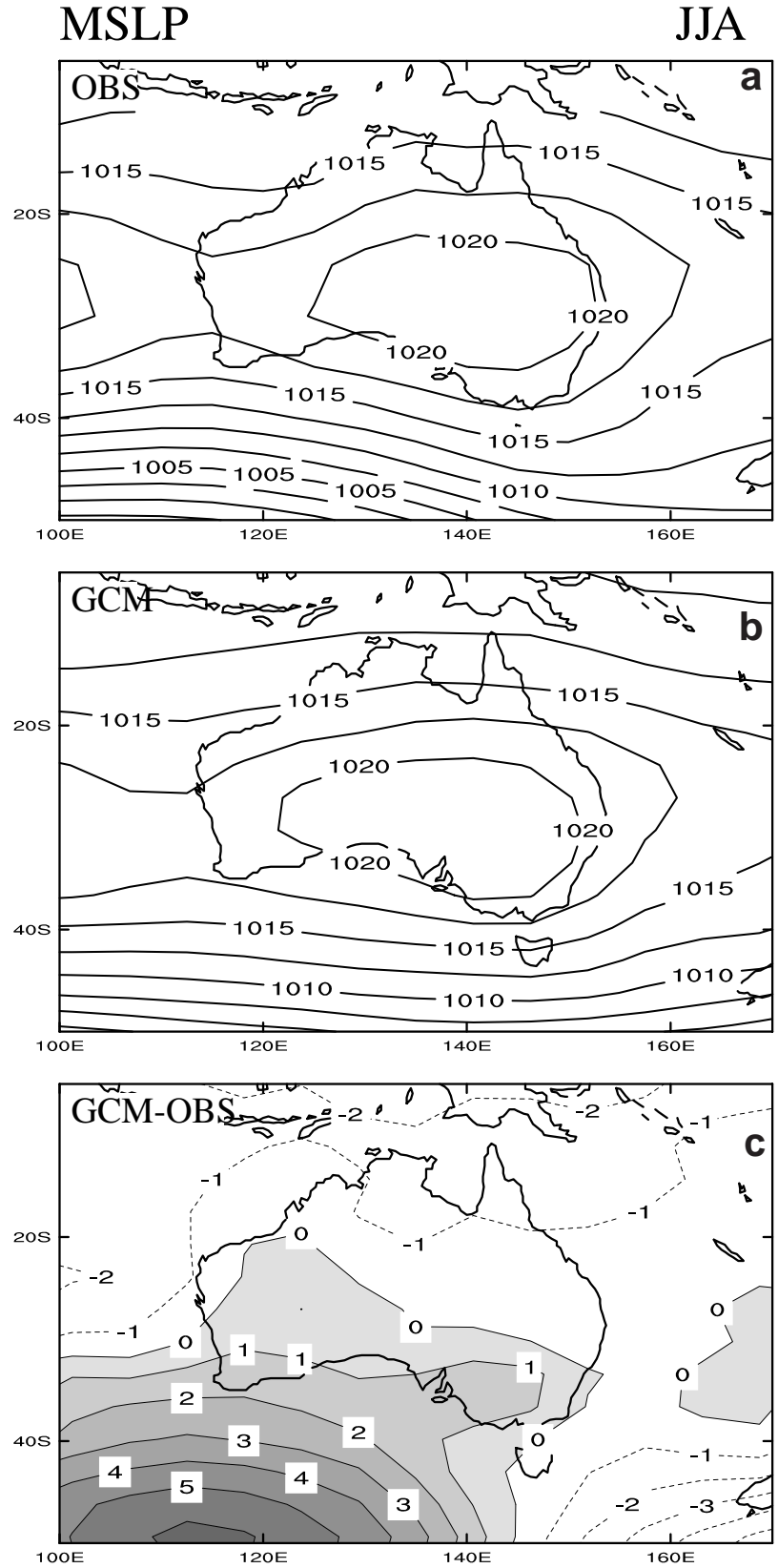

Fig. 8. Mean sea level pressure in JJA: (a) observed and (b) simulated in the GCM. (c) The difference between GCM results and the observations. Units are $\mathrm{hPa}$

tion of the spatial patterns of temperature and rainfall. Most of the improvements can be related to the better representation of the mountains of Victoria in DARLAM (changes in atmospheric circulation between the 2 models were quite small). However, the simulation of rainfall still has some significant deficiencies. It would seem these mostly arise due to errors in the simulation of atmospheric circulation as provided by the GCM in JJA and due to a tendency for rainfall in DARLAM to be too high over mountainous areas in summer.

\section{SIMULATION OF CLIMATE UNDER $2 \times \mathrm{CO}_{2}$ CONDITIONS}

\subsection{Rainfall}

Fig. 10 shows the simulated percentage changes in seasonal rainfall over the study domain for a doubling of $\mathrm{CO}_{2}$ according to both the GCM and DARLAM. Statistical significance at the $95 \%$ confidence level is assessed using Student's $t$-test. The GCM shows a simple pattern of rainfall decreases over Victoria in all seasons. The decreases are largest in the north, particularly in JJA and DJF, when they are also statistically significant. The decreases taper to no change or a very slight increase in the far south of the domain. The enhanced greenhouse climate in DARLAM is consider-

DARLAM60 - OBS
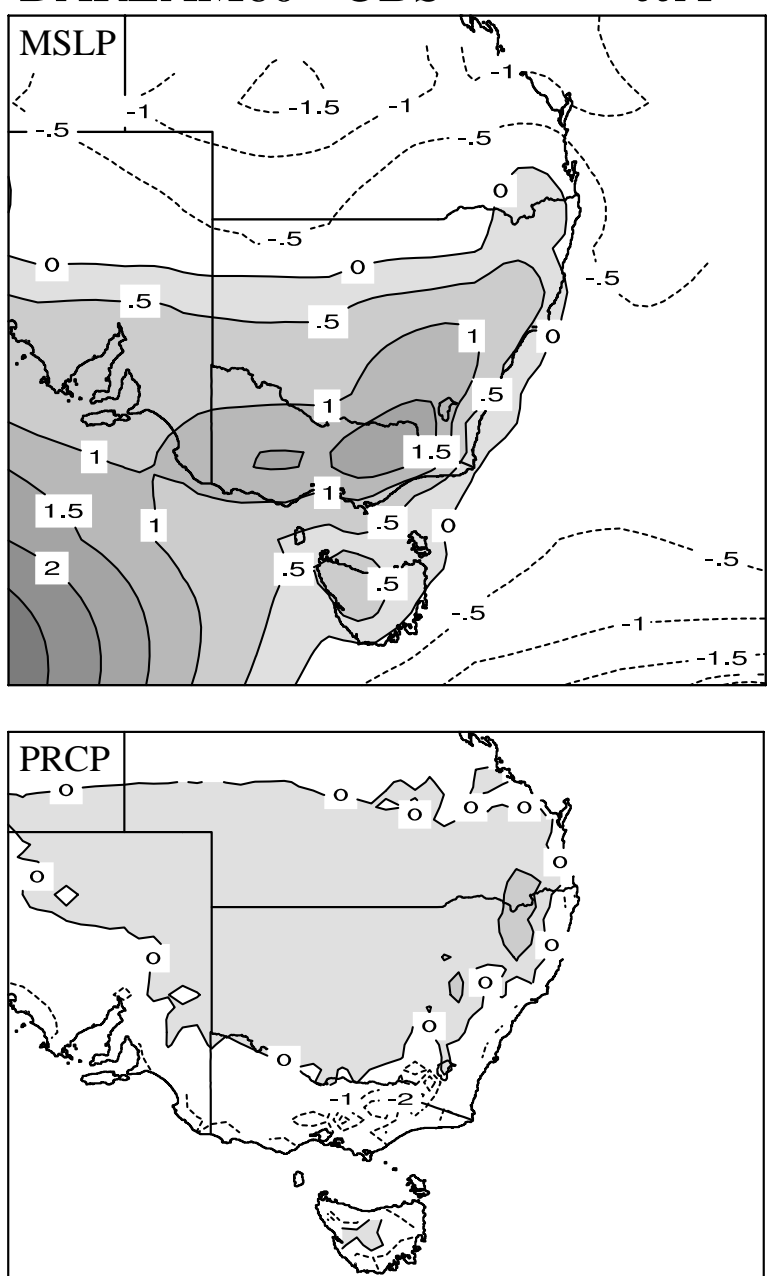

Fig. 9. Difference between the DARLAM simulation and observations for (a) mean sea level pressure and (b) rainfall in JJA. Units are $\mathrm{hPa}$ and $\mathrm{mm} \mathrm{d}^{-1}$ respectively 
GCM
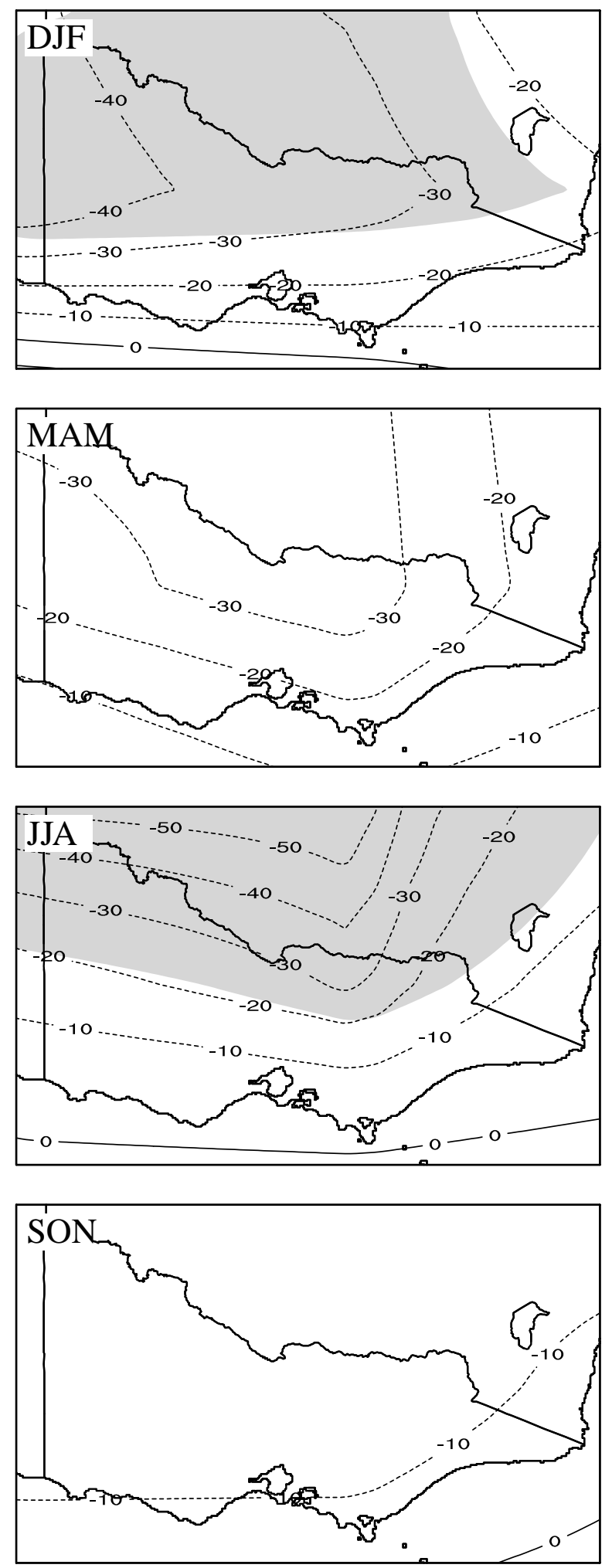

DARLAM60
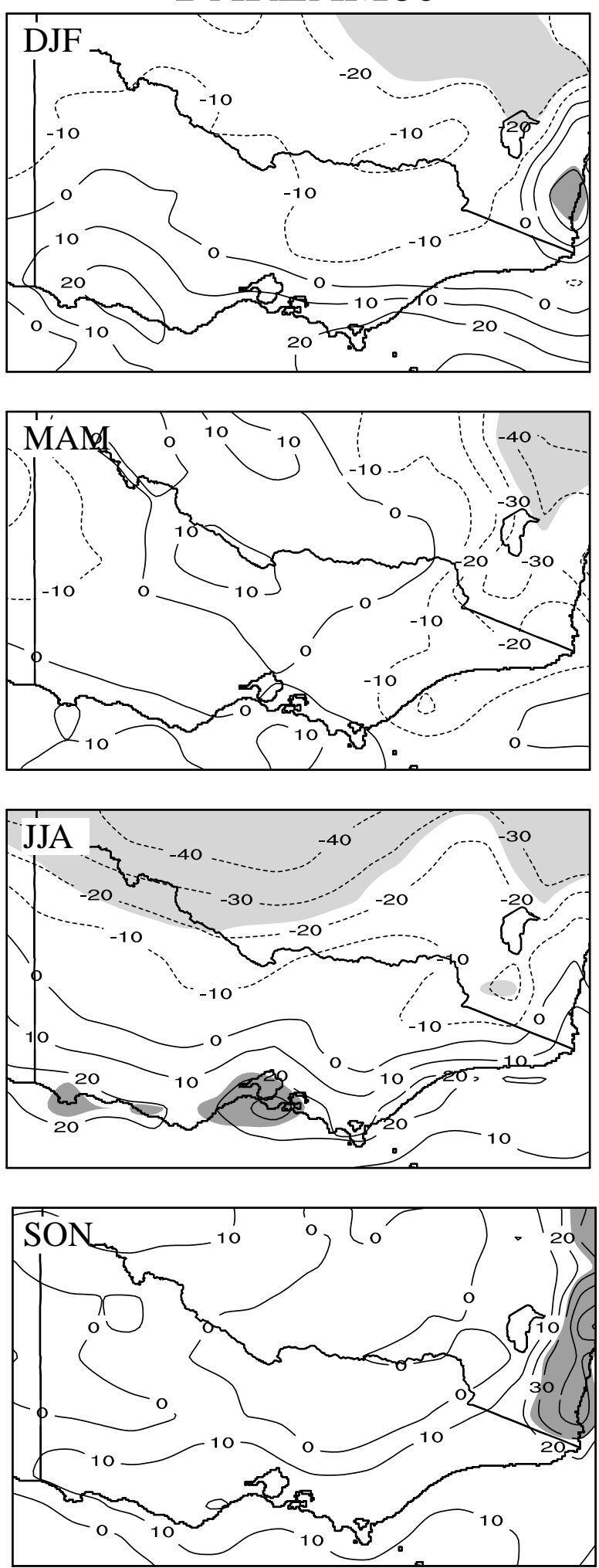

Fig. 10. Percentage change in mean seasonal rainfall under $2 \times \mathrm{CO}_{2}$ conditions as simulated by the GCM and by DARLAM. Areas of change statistically significant at the $95 \%$ level are shaded 


\section{DARLAM60-GCM}
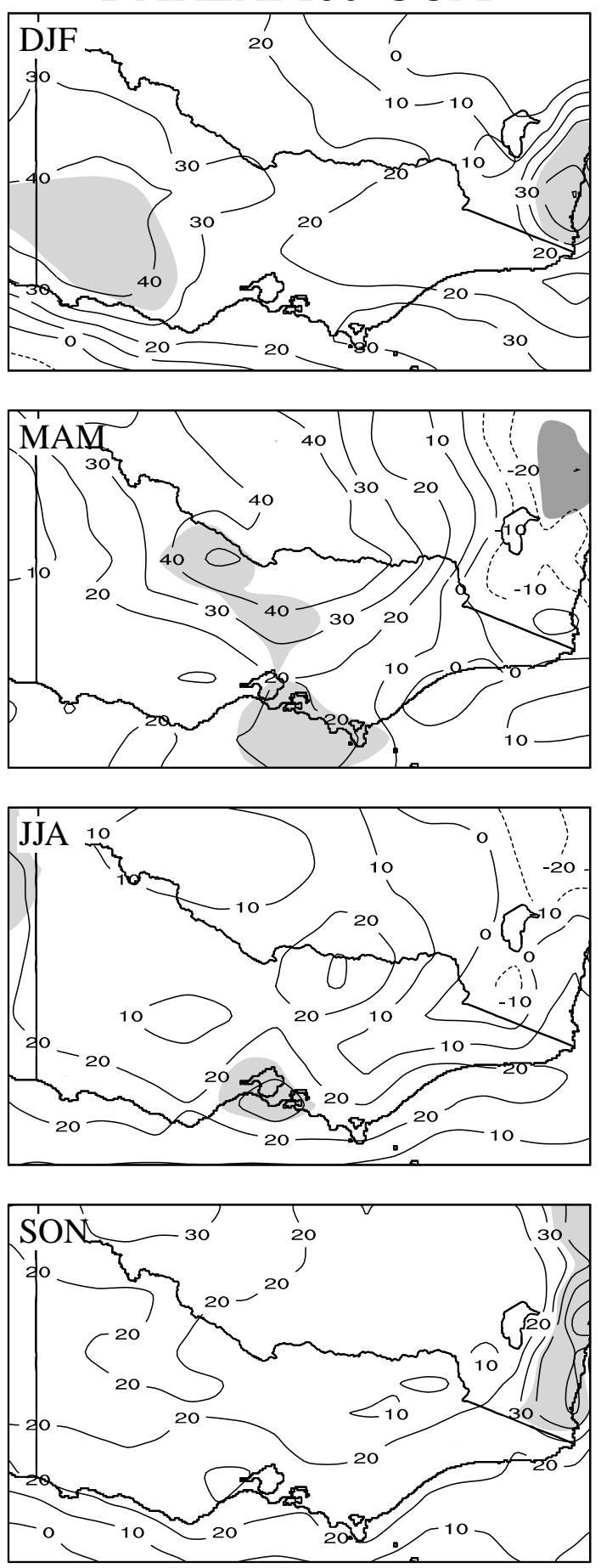

Fig. 11. Difference in the percentage change in seasonal rainfall between DARLAM and the GCM. Areas of change statistically significant at the $95 \%$ level are shaded

ably wetter and more structured than that of the GCM. South of the Divide, increases predominate, particularly in JJA and SON, when they exceed $10 \%$. In some regions the increases are statistically significant in JJA. North of the Divide, decreases still predominate, but these are weaker, and areas of statistically significant decrease have retreated into the far north or northeast of the domain.

The contrast between the GCM and DARLAM pattern of change is most interesting in JJA, when many of the changes are statistically significant. The boundary between the increased rainfall and decreased rainfall lies south of the continent in the GCM, but along the Divide in DARLAM. Consistent with the greater plausibility of the DARLAM results, studies of patterns of interannual rainfall variations over Victoria (e.g., Whetton 1988) demonstrate the importance of the Divide as a climatic barrier.

As the change in the patterns of simulated rainfall change described above is a potentially important result, assessment of its statistical significance was undertaken. The GCM data were interpolated to the DARLAM grid, and for both models the $10 \mathrm{yr}$ of seasonal data were expressed as anomalies from their $10 \mathrm{yr}$ means. At each grid point on the common grid, a $t$-test was performed on the difference between the mean changes in the 2 models. The results are shown in Fig. 11. There are areas of change significant at the $95 \%$ level in each season, mainly in the southern, southwestern and far eastern parts of the domain.

The results suggest that, with increased resolution, Victoria, particularly in the south, has increasingly come under the influence of the rainfall increases which are characteristic of the oceans to the south of Australia. The increase in the importance of this maritime factor is associated with marked improvements in the representation of the State's topography and patterns of current climate. Changes in the sign of simulated rainfall change in mountainous areas due to increased resolution have been observed in a nested simulation for North America (Giorgi et al. 1994).

\subsection{Daily maximum and minimum temperature}

Fig. 12 shows the simulated change in daily maximum temperature for DJF and JJA for each simulation. High resolution has not led to marked changes in simulated warming in the region, although the warmings are up to $1^{\circ} \mathrm{C}$ less in DJF. This may reflect increased soil moisture in DARLAM (not shown) compared to the GCM which is associated with the weakening of rainfall decreases in DARLAM. The GCM pattern of less warming in coastal areas is more clearly apparent in the DARLAM results. The results for daily minimum temperature (Fig. 13) differ little from the GCM results, although DARLAM shows a tendency for reduced warming at higher elevation in the east of the State. 


\section{GCM}
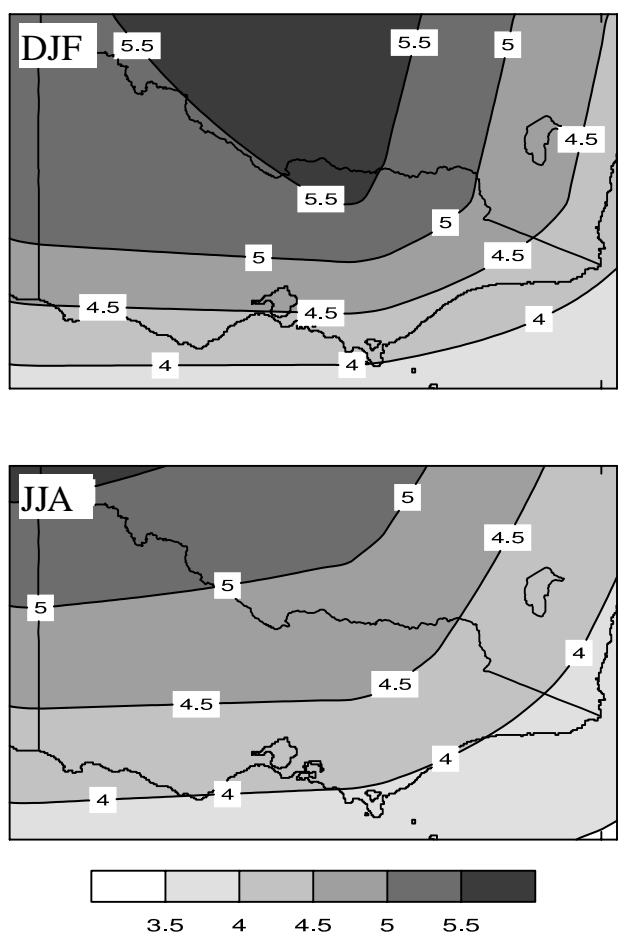

DARLAM60
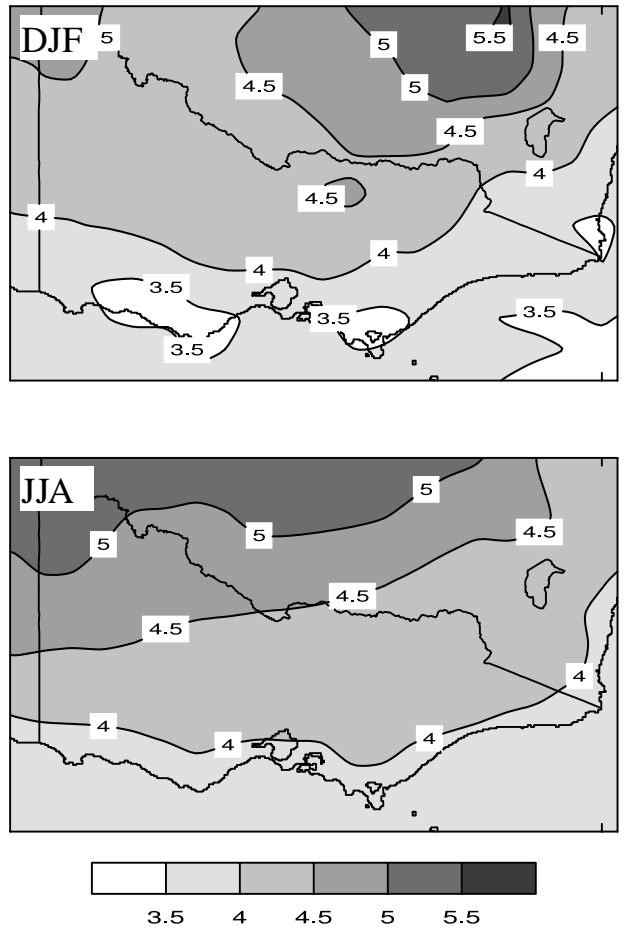

Fig. 12. Change in mean DJF and JJA daily maximum temperature under $2 \times \mathrm{CO}_{2}$ conditions as simulated by the GCM and by DARLAM. Units in ${ }^{\circ} \mathrm{C}$

\section{DARLAM-BASED SCENARIO FOR CLIMATE CHANGE OVER VICTORIA}

The $2 \times \mathrm{CO}_{2}$ simulated changes in regional rainfall and maximum and minimum temperature were used to prepare scenarios of climate change for the years 2030 and 2070 for use in impact studies. Using the global annual mean warming simulated by the host GCM for $2 \times \mathrm{CO}_{2}$ conditions $\left(4.3^{\circ} \mathrm{C}\right)$, the DARLAM patterns of change in rainfall and temperature were reexpressed in terms of warming per ${ }^{\circ} \mathrm{C}$ of global warming and percentage rainfall change per ${ }^{\circ} \mathrm{C}$ of global warming (not shown). This information was then combined with scenarios for the evolution of global warming for 1990-2100 which take into account uncertainty in projecting global warming. This scaling approach has been used by a number of researchers for various parts of the world (e.g., Hulme et al. 1992, Rotmans et al. 1994, Kenny et al. 1995). The reliability of this method has only been demonstrated for temperature (Mitchell et al. 1999), and thus the precipitation results presented here should be viewed with caution.

The global warming scenarios used are those given in the Intergovernmental Panel on Climate Change (IPCC) assessment (Houghton et al. 1996). Table 6 presents these warming scenarios for 2030 and 2070. The broad range of warming indicated in the table comes from making allowance for 3 important sources of uncertainty: the range of greenhouse gas emission scenarios considered plausible by the IPCC; the range of estimates of the sensitivity of global climate to increased greenhouse forcing (usually represented by the IPCC as the estimated global equilibrium warming range of 1.5 to $4.5^{\circ} \mathrm{C}$ for a doubling of $\mathrm{CO}_{2}$ ); and the extent of any cooling effect due to sulfate aerosol emissions. Two different assumptions were explored for aerosols: one where the aerosol emissions increase as greenhouse gas emissions grow, and another where aerosol emissions are assumed to remain constant at 1990 levels.

In preparing the Victorian scenarios, the global warming ranges given in the second column of Table 6 were used $\left(0.4\right.$ to $1.2^{\circ} \mathrm{C}$ by 2030 and 0.7 to $3.0^{\circ} \mathrm{C}$ by

Table 6. Global warming scenarios $\left({ }^{\circ} \mathrm{C}\right)$ from Houghton et al. (1996)

\begin{tabular}{|ccc|}
\hline Year & Constant aerosols & Varying aerosols \\
\hline 2030 & $0.4-1.2$ & $0.4-0.8$ \\
2070 & $0.7-3.0$ & $0.7-2.1$ \\
\hline
\end{tabular}




\section{GCM}
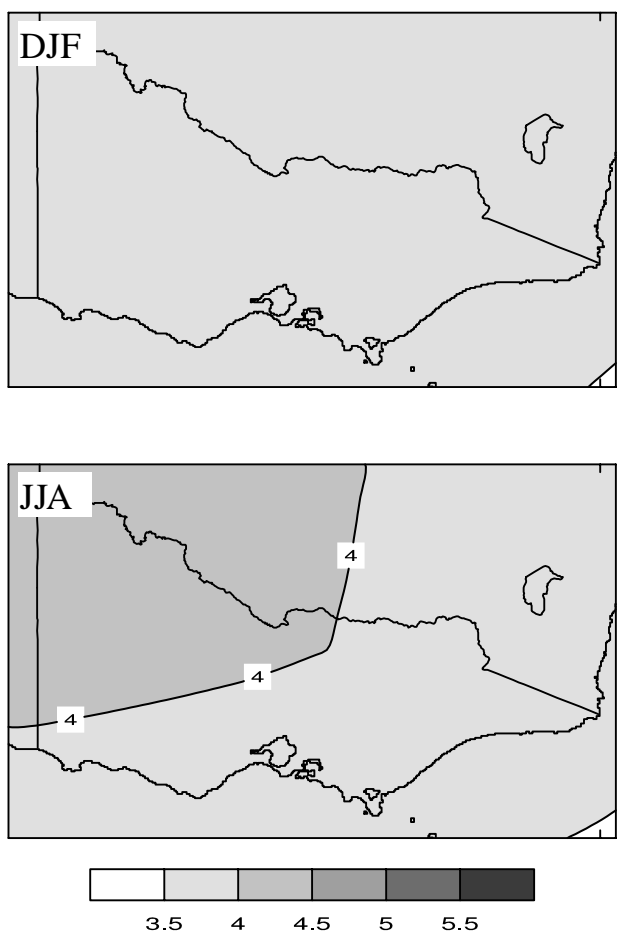

\section{DARLAM60}
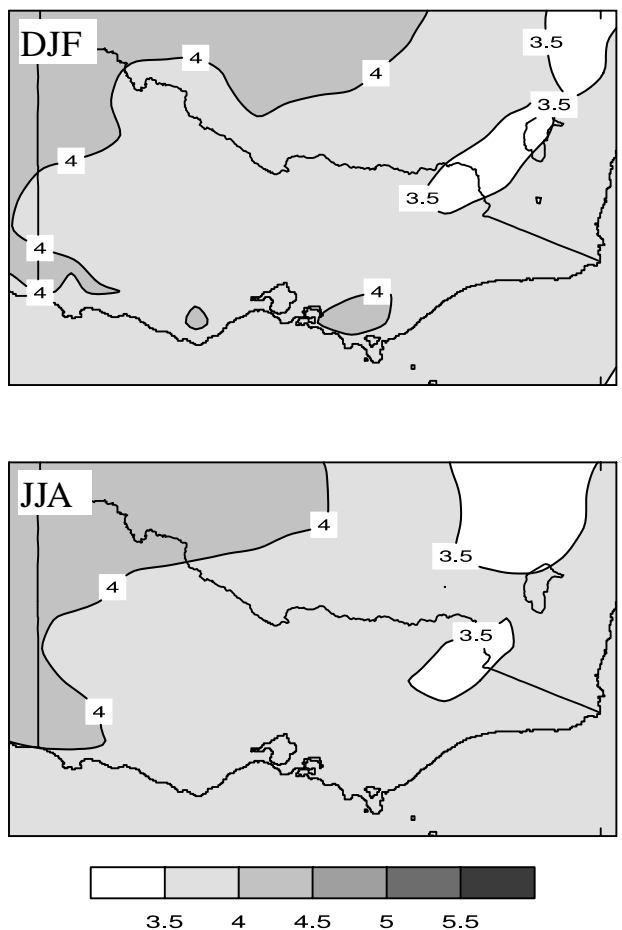

Fig. 13. Change in mean DJF and JJA daily minimum temperature under $2 \times \mathrm{CO}_{2}$ conditions as simulated by the GCM and by DARLAM. Units in ${ }^{\circ} \mathrm{C}$

2070). This choice recognises the fact that aerosol cooling is considerably weaker over Australia than it is in the global average (most of the cooling occurs in the northern hemisphere close to the main sulfate sources). Use of the varying aerosol warming scenarios in conjunction with the DARLAM results (which do not contain an aerosol effect) would have considerably overestimated the cooling effect of sulfate aerosols in the Australian region.

To illustrate the results of this approach, high and low case changes in rainfall in JJA by 2030 and 2070 are given in Fig. 14. In this case, and for the other seasons and variables, the spatial patterns are the same as the corresponding ones in Figs. 10, 12 \& 13, but of different magnitude.

By 2030, the increase in maximum temperature over northern Victoria ranges from around $0.4^{\circ} \mathrm{C}$ in the low case through to around $1.4^{\circ} \mathrm{C}$ in the high case. In southern Victoria, the range is 0.3 to $1.2^{\circ} \mathrm{C}$. Warming is a little higher in MAM and SON than it is in the other 2 seasons. The increase in minimum temperature across the State ranges from around $0.4^{\circ} \mathrm{C}$ in the low case to around $1.1^{\circ} \mathrm{C}$ in the high case. In DJF, JJA, and SON rainfall increases in southern Victoria by around $2 \%$ in the low case and $5 \%$ in the high case. Decreases of similar magnitude are present in northern Victoria in DJF and JJA and in eastern Victoria in MAM. Otherwise the changes in rainfall are negligible.

The corresponding scenario for 2070 contains considerably larger changes in climate. The increase in maximum temperature in northern Victoria ranges from 0.7 to $3.5^{\circ} \mathrm{C}$ between the high and low cases, and that in southern Victoria from 0.6 to $3.0^{\circ} \mathrm{C}$. Changes in minimum temperature are around $0.6^{\circ} \mathrm{C}$ across the State in the low case and nearly $3.0^{\circ} \mathrm{C}$ in the high case. The increases in rainfall in southern Victoria in DJF, JJA and SON range from around $2 \%$ in the low case to around $10-15 \%$ in the high case. The decreases in rainfall in northern Victoria in DJF and JJA and in eastern Victoria in MAM are around 3\% in the low case and $10-15 \%$ in the high case. It should be noted that rainfall changes as large as $10-15 \%$ are small compared to the observed natural variability of rainfall in the region. Year-to-year variations of $50 \%$ or more are typical (Whetton et al. 2000b).

\subsection{Reliability of the DARLAM scenario}

The DARLAM-simulated patterns of rainfall change over Victoria presented in the 2 previous sections differ greatly from those provided by the host GCM. 
Given that the current climate simulation over the region has improved with increasing resolution, it is likely that the DARLAM patterns of change are more realistic than those provided by the coarser resolution model. However, to fully assess the reliability in general of the DARLAM scenario, a range of further issues needs to be considered. These issues are outlined in this section, and the research that would be needed to address them is proposed. However a full assessment cannot be undertaken within the scope of the present paper.

How representative are the results of the enhanced greenhouse signal of the models used? The results obtained here represent a combination of the enhanced greenhouse signal of the combined models and differences due to model internal variability (noise). The latter, which is not of interest in the current context, can partially or fully obscure the signal (see discussion in Hulme et al. 1999). In the current study the precipitation signal is relatively small compared to internal variability. This is reflected in the fact that simulated rainfall changes as large as $20 \%$ were not necessarily statistically significant. Given that a signal of this magnitude may be important in terms of impacts, it can be said that the current sample is not adequate for the purposes of preparing appropriate climate change scenarios. Signal to noise may be increased through extending the simulation period or through averaging over ensembles. In the present case, some (indirect) assessment can be made of the effect of increased sample size by examining simulated precipitation changes in a longer sample from the host GCM. Fig. 15 shows Australia-wide DJF results for a $30 \mathrm{yr}$ sample compared to the $10 \mathrm{yr}$ sample used for nesting. It is notable that the drying over northern Victoria is considerably weaker in the full period than in the $10 \mathrm{yr}$ period. Differences in the other seasons were not as great. In the light of this result, the summer rainfall decreases simulated by DARLAM for northern Victoria must be considered less reliable.

To what extent do the errors in the control climate simulation of the GCM and DARLAM bias the enhanced greenhouse simulated changes? This is a difficult question to address. A specific example of this question might be: 'How much is the pattern of simulated winter rainfall change over Victoria in error because of the tendency for the GCM and DARLAM to simulate too little winter rainfall over the State?' The potential for significant bias exists. This is because the simulated pattern of rainfall change (decreases in the north, increases in the south) suggests that rainfall changes will be different for the different types of rainbearing systems which affect the State, and the current climate error suggests that the relative importance of these various rain-bringing systems may be distorted in the simulation. There would be some scope to estimate the bias and to correct for it with appropriately designed statistical studies, but the substantial re-

\section{LOW}
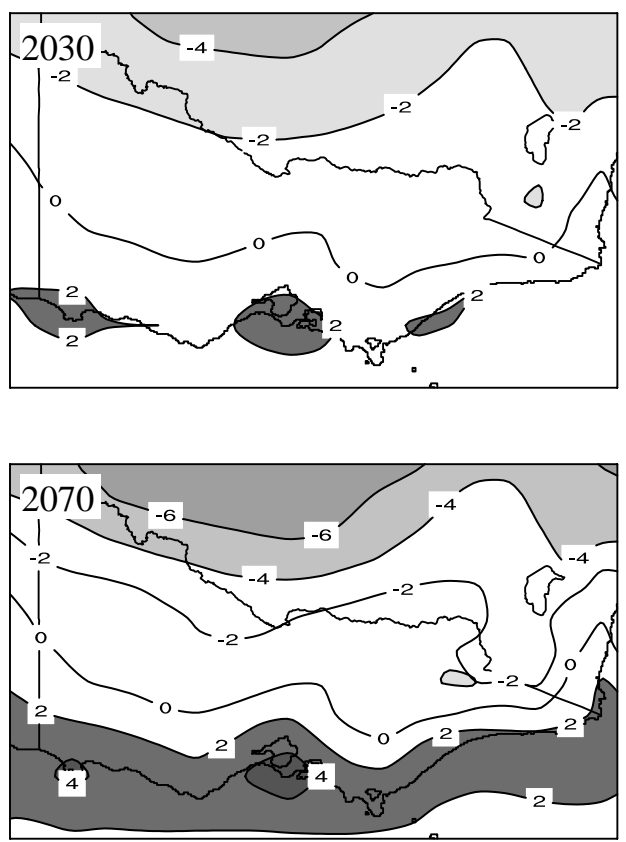

$\mathrm{HIGH}$
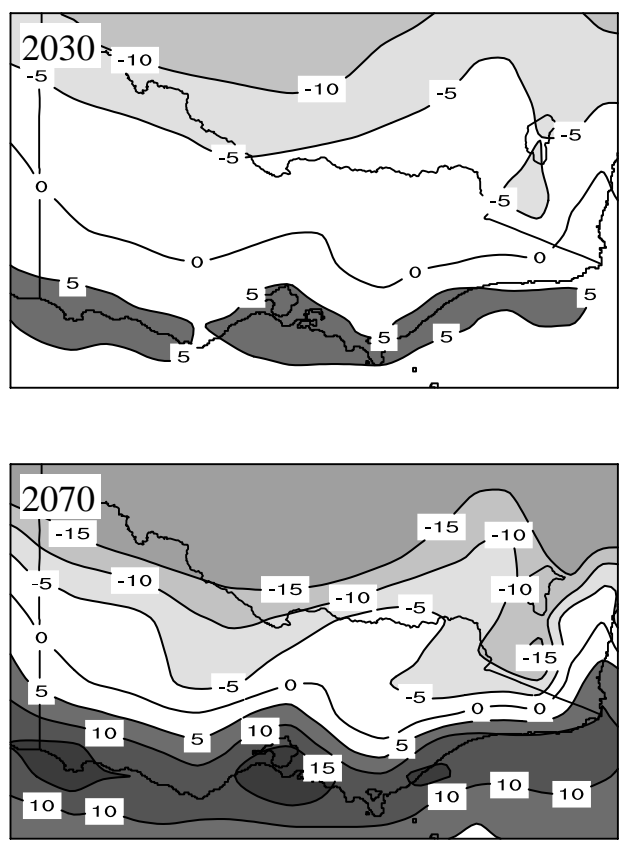

Fig. 14. High and low case scenarios for JJA rainfall change in 2030 and 2070 in \% 

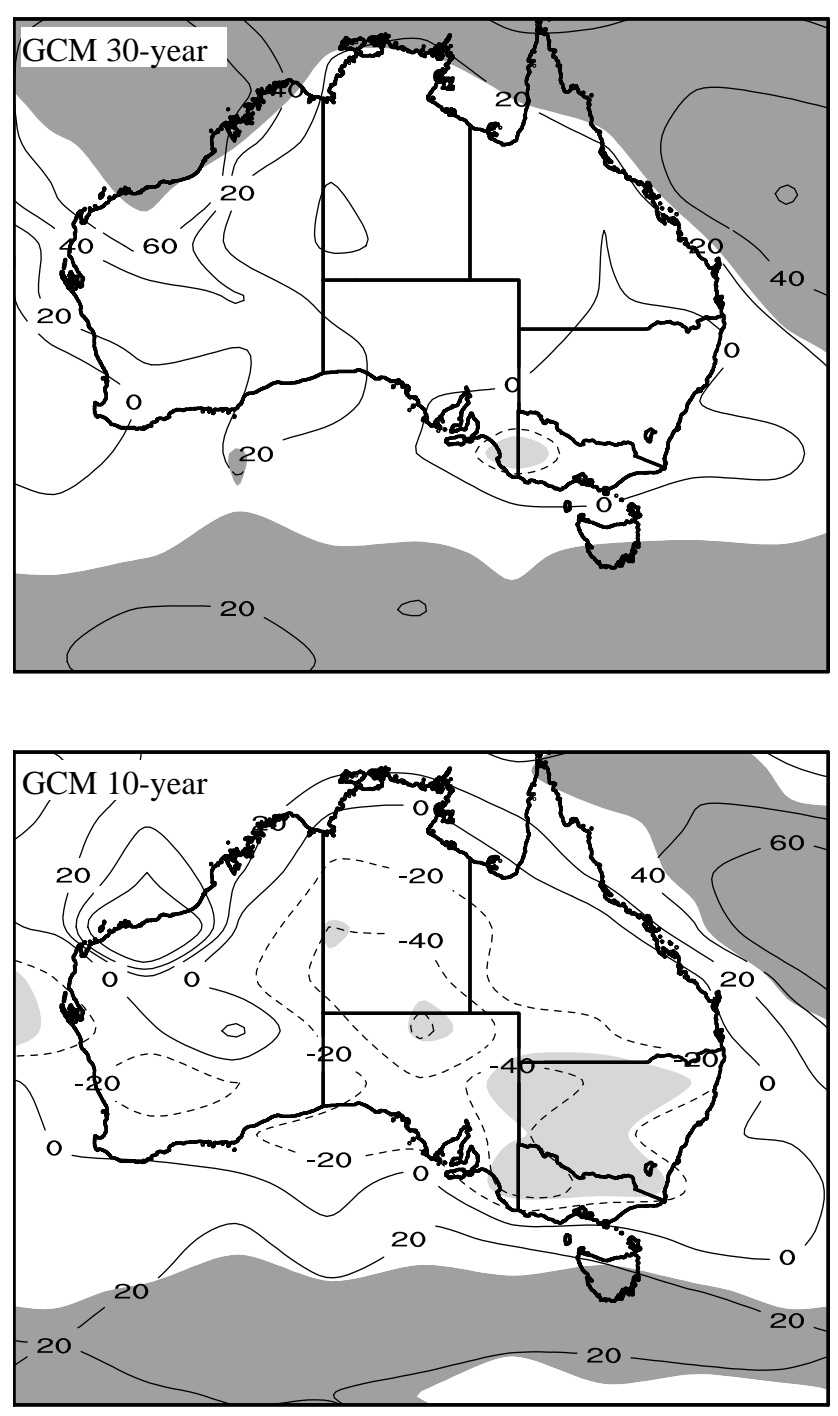

Fig. 15. Simulated summer rainfall change in the $30 \mathrm{yr}$ sample from the host GCM, and in the $10 \mathrm{yr}$ sample used for nesting DARLAM. Areas of change statistically significant at the $95 \%$ level are shaded

search effort this would require may be best directed towards reducing the errors in the host GCM and the regional model.

Use of different global and regional models and regionalisation methods. It is reasonable to presume that if DARLAM were nested in a number of other GCM experiments, a range of different regional model results would be obtained much as is seen amongst the GCMs presented in Fig. 2. DARLAM is nested in new CSIRO simulations as they become available (a simulation has been completed nested in the CSIRO coupled ocean-atmosphere GCM under a transient increase in $\mathrm{CO}_{2}$-it will be discussed in a subsequent paper), but is not usually nested in GCM simulations from other institutions. Such experiments would need to be undertaken to fully assess this uncertainty. It would also be appropriate to investigate alternative regional models nested with the CSIRO GCM, and alternative regionalisation methods such as statistical downscaling (e.g., von Storch et al. 1993, Gyalistras et al. 1994, Hewitson \& Crane 1996, Wilby \& Wigley 1997). Statistical downscaling has certain advantages over regional modelling with regard to impact applications, such as the ability to produce ensemble data sets. The dependence of high resolution scenarios on the particular global model used to obtain them could also be assessed by applying statistical downscaling to alternative GCM results, although it should be noted that results can differ significantly from those obtained directly with a regional model (Jones et al. 1997, Mearns et al. 1999b, Murphy 2000).

The range of results given by current GCMs need not encompass the full range of all plausible future climates. Although there has been much development in global climate modelling in recent years, many important deficiencies remain in GCMs. In particular, some factors which are likely to be quite important in determining patterns of climate change in the Australian region, such as ocean behaviour changes and the ENSO, are poorly represented in climate models. This general issue of reliability of global climate modelling is beyond the scope of this discussion, but is summarised in Houghton et al. (1996).

Taking the above into account, it may be concluded that at the time of its completion, the DARLAM scenario (encompassing the high and low cases) was the best single scenario available for use in climate change impact assessment in the Victorian region. It provided patterns of change that were likely to be physically more realistic than those provided by the host GCM. However, the above discussion also makes it clear that different, but equally plausible, scenarios could be obtained by other means. Given these considerations, we recommend that any use of the present DARLAM scenario in impact studies should be accompanied by some discussion of the sensitivity of the impact results to plausible alternative scenarios. To assist in this, CSIRO has also issued generalised scenarios at coarse horizontal resolution based on a broad range of GCM results (CSIRO 1996).

\section{CONCLUDING DISCUSSION}

This paper describes research aimed at providing high resolution climate change scenarios for Victoria. Current and enhanced greenhouse climate over Victoria was simulated at a horizontal resolution of $60 \mathrm{~km}$ 
using DARLAM nested in the slab ocean version of the CSIRO GCM. The key findings of the study are as follows:

- Temperature over Victoria is substantially better simulated in DARLAM than in the host GCM. Most of the improvements can be related to the better representation of the mountains of Victoria in DARLAM. There is also significant improvement in the spatial pattern of rainfall. However, some poor features of the simulation of the seasonal cycle of rainfall have not been improved with increasing resolution. There is evidence to suggest that these are partly due to errors in the simulation of atmospheric circulation provided by the host GCM.

- Under $2 \times \mathrm{CO}_{2}$ conditions, DARLAM simulates patterns of rainfall and temperature change which differ significantly from those provided by the host GCM. Broadly, with increasing resolution a strengthening of a pattern of rainfall increases in southern Victoria and a weakening of simulated rainfall decreases for northern Victoria is seen. This pattern applies throughout most of the year. Given the improvement in the DARLAM simulation of current climate relative to the GCM, the DARLAM changes in the enhanced greenhouse simulation are likely to represent increased realism, although this cannot be guaranteed. Indeed the fact that winter rainfall in southern Victoria increases in the latest DARLAM simulation, but decreases in the host GCM, demonstrates the importance of high resolution modelling of climate change in topographically complex regions.

- Although the DARLAM scenario could be considered the best single scenario available for Victoria at the time it was prepared, it would be inadvisable to solely use this information in assessing regional climate change impacts. Different, but equally plausible, scenarios could be obtained by nesting DARLAM in other GCMs, or simply by extending the duration of the current experiment. Our assessment is that the rainfall changes simulated by DARLAM in summer may be most sensitive to such changes. Given these considerations, any use of the DARLAM scenario in impact studies should be accompanied by some analysis of the sensitivity of the impact results to plausible alternative scenarios.

- The reliability of future DARLAM-based scenarios may be enhanced by improving the realism of DARLAM and the host GCM, and by undertaking simulations of longer duration or ensemble simulations to obtain more statistically robust results. There is also a need to nest DARLAM in other GCMs, particularly in transient coupled atmosphere-ocean GCMs, which should give a more realistic simulation of oceanic influences on climate change.
It would also be desirable to analyse how well daily variability (daily extreme rainfall events) and interannual variability (dry years, wet years, etc.) are simulated in the current climate simulation, and how these are simulated to change in the enhanced greenhouse run. The results from such a study would be more relevant to certain climate change impact areas than estimated changes in mean climate.

Although there is clearly great potential to increase the realism of regional climate change scenarios through nested regional modelling, scenario developers still need to consider the results of coarse-scale GCMs. Because running regional models is technically demanding and must be done separately for each region of interest, simulations can be of short duration and may not use the most up-to-date GCM as a host, or more than one such host GCM. However, even when the regional model results suffer from these disadvantages, they can, as we have seen in the current study, reveal important systematic differences from the results of the host GCM which may be generally applicable and hence would need to be considered in regional scenario development.

Acknowledgements. This work was funded by the Victorian Department of Natural Resources and Environment and contributes to the CSIRO Climate Change Research Program.

\section{LITERATURE CITED}

Boer GJ, Flato G, Reader MC, Ramsden D (in press) A transient climate change simulation with greenhouse gas and aerosol forcing: experimental design and comparison with the instrumental record for the 20th century. Clim Dyn

Brereton R, Bennett S, Mansergh I (1995) Enhanced greenhouse climate change and its potential effect on selected fauna of south-eastern Australia: a trend analysis. Biol Conserv 72:339-354

Bureau of Meteorology (1988) Climatic averages Australia. Bureau of Meteorology, Canberra

Chiew FHS, Whetton PH, McMahon TA, Pittock AB (1995) Simulation of the impacts of climate change on runoff and soil moisture in Australian catchments. J Hydrol 167 : 121-147

Christensen JH, Machenhauer B, Jones RG, Schar C, Ruti PM, Castro M, Visconti G (1997) Validation of present-day regional climate simulations over Europe: LAM simulations with observed boundary conditions. Clim Dyn 13: 489-506

Colman RA, McAvaney BJ, Fraser JR, Power SB (1994) Annual mean meridional energy transport modelled by a general circulation model for present and $2 \times \mathrm{CO}_{2}$ equilibrium climates. Clim Dyn 10:221-229

CSIRO (1992) Climate change scenarios for the Australian Region. CSIRO Division of Atmospheric Research, Aspendale

CSIRO (1996) Climate change scenarios for the Australian region. CSIRO Division of Atmospheric Research, Aspendale

Cubasch U, Hasselmann K, Hock H, Maier-Reimer E, Mikolajewicz U, Santer B, Sausen R (1992) Time-dependent 
greenhouse warming computations with a coupled oceanatmosphere model. Clim Dyn 8:55-69

Giorgi F, Mearns LO (1999) Introduction to special section: regional climate modeling revisited. J Geophys Res 104: 6335-6352

Giorgi F, Brodeur CS, Bates GT (1994) Regional climate change scenarios over the United States produced with a nested regional climate model. J Clim 7:375-399

Giorgi F, Mearns L, Shields S, McDaniel L (1998) Regional nested model simulations of present day and $2 \times \mathrm{CO}_{2}$ climate over the Central Great Plains of the United States. Clim Change 40:457-493

Gregory JM, Mitchell JFB (1995) Simulation of daily variability of surface temperature and precipitation over Europe in the current and $2 \times \mathrm{CO}_{2}$ climates using the UKMO highresolution climate model. Q J R Meteorol Soc 121: 1451-1476

Gyalistras D, von Storch H, Fischlin A, Beniston M (1994) Linking GCM-simulated climatic changes to ecosystem models: case studies of statistical downscaling in the Alps. Clim Res 4:167-189

Hassall and Assoc (1998) Climate change scenarios and managing the scarce water resources of the Macquarie River. Australian Greenhouse Office, Canberra

Hennessy KJ, Whetton PH, Wu X, McGregor JL, Katzfey JJ, Nguyen KC (1997) Fine resolution climate change scenarios for New South Wales: research undertaken for the New South Wales Environment Protection Authority. NSW Environment Protection Authority, Chatswood, NSW

Hewitson BC, Crane RG (1996) Climate downscaling: techniques and application. Clim Res 7:85-95

Hirst AC, Gordon HB, O'Farrell SP (1996) Global warming in a coupled climate model including oceanic eddy-induced advection. Geophys Res Lett 23:3361-3364

Houghton JT, Jenkins GJ, Ephraums JJ (1990) Climate change, the IPCC scientific assessment. Cambridge University Press, Cambridge

Houghton JT, Meira Filho LG, Callander BA, Harris N, Kattenberg A, Varney SK (1996) Climate change 1995: Contribution of Working Group 1 to the Second Assessment Report of the IPCC. Cambridge University Press, Cambridge

Hulme M, Wigley TML, Jiang J, Zhao ZC, Wang F, Ding Y, Leemans R, Markham A (1992) Climate change due to the greenhouse effect and its implications for China. WWF International, Gland

Hulme M, Barrow EM, Arnell N, Harrison PA, Downing TE, Johns TC (1999) Relative impacts of human-induced climate change and natural climate variability. Nature 397 : 688-691

Hutchinson MF, Bischoff RJ (1983) A new method for estimating the spatial distribution of mean seasonal and annual rainfall applied to the Hunter Valley, New South Wales. Aust Meteorol Mag 31:179-184

Jones RG, Murphy JM, Noguer M, Keen AB (1997) Simulation of climate change over Europe using a nested regional-climate model. II: comparison of driving and regional model responses to a doubling of carbon dioxide. Q J R Meteorol Soc 123:265-292

Jones RN, Hennessy KJ, Page CM, Pittock AB, Suppiah R, Walsh KJE, Whetton PH (2000) An analysis of the effects of the Kyoto protocol on Pacific Island countries. South Pacific Regional Environment Program, Apia

Karoly DJ, Kelly GAM, Le Marshall JF (1987) The Australian southern hemisphere climatology data tape. BMRC Research Report 7, Bureau of Meteorology, Melbourne
Katzfey JK (1993) Month-long nested simulations for eastern Australia. In: Fourth International Conference on Southern Hemisphere Meteorology and Oceanography, Hobart. American Meteorological Society, Boston, p 302-303

Kenny GJ, Warrick RA, Mitchell ND, Mullan AB, Salinger MJ (1995) CLIMPACTS: an integrated model for assessment of the effects of climate change on the New Zealand environment. J Biogeogr 22:883-895

Leung LR, Ghan SJ (1995) A subgrid parameterization of orographic precipitation. Theor Appl Climatol 52:95-118

Lunkeit F, Sausen R, Oberhuber JM (1994) Climate simulations with the global coupled atmosphere-ocean model ECHAM/OPYC. Part 1: Present-day climate and ENSO events. Max Planck Institute Report 132, Hamburg

Machenhauer B, Windelband M, Botzet M, Jones RG, Deque M (1996) Validation of present-day regional climate simulation over Europe: nested LAM and variable resolution global model simulations with observed or mixed layer ocean boundary conditions. Max Planck Institute Report 191, Hamburg

Manabe S, Stouffer RJ, Spelman MJ, Bryan K (1991) Transient responses of a coupled ocean-atmosphere model to gradual changes of atmospheric $\mathrm{CO}_{2}$. Part I: Annual mean response. J Clim 4:785-818

Marinucci MR, Giorgi F, Beniston M, Wild M, Tschuck P, Ohmura A, Bernasconi A (1995) High resolution simulations of January and July climate over the western Alpine region with a nested regional modeling system. Theor Appl Climatol 51:119-138

McFarlane NA, Boer GJ, Blanchet JP, Lazare M (1992) The Canadian Climate Centre second-generation general circulation model and its equilibrium climate. J Clim 5: 1013-1044

McGregor JL (1994) Nested climate models for regional studies. In: Jakeman AJ, Pittock AB (eds) Climate Impact Assessment Methods for Asia and the Pacific: Proceedings of a Regional Symposium, Canberra. Australian International Development Assistance Bureau, Canberra, p 37-42

McGregor JL (1997) Regional climate modelling. Meteorol Atmos Phys 63:105-117

McGregor JL, Walsh KJE (1994) Climate change simulations of Tasmanian precipitation using multiple nesting. J Geophys Res 99:20889-20905

Mearns LO, Giorgi F, McDaniel L, Shields C (1995) Analysis of daily variability of precipitation in a nested regional climate model: comparison with observations and doubled $\mathrm{CO}_{2}$ results. Global Planet Change 10:55-78

Mearns LO, Easterling W, Hays C (1998) The effect of spatial scale of climate change scenarios on the determination of impact: an example of agricultural impacts on the Great Plains. In: Congbin Fu (ed) Proceedings of the International Workshop on Regional Modelling of the General Monsoon System in Asia. The Global Change SysTem for Analysis, Research and Training (START), Beijing, p 70-73

Mearns LO, Mavromatis T, Tsvetsinskaya E, Hays C, Easterling W (1999a) Comparative responses of EPIC and CERES crop models to high and low spatial resolution climate change scenarios. J Geophys Res 104:6623-6646

Mearns LO, Bogardi I, Giorgi F, Matyasovszky I, Palecki M (1999b) Comparison of climate change scenarios generated from regional climate model experiments and statistical downscaling. J Geophys Res 104:6603-6621

Mitchell JFB, Johns TC (1997) On modification of global warming by sulphate aerosols. J Clim 10:245-267

Mitchell JFB, Johns TC, Eagles M, Ingram WJ, Davis RA (1999) Towards the construction of climate change scenarios. Clim Change 41:547-581 
Murphy J (2000) Predictions of climate change over Europe using statistical and dynamical downscaling techniques. Int J Climatol 20:489-501

Pittock AB (1988) Actual and anticipated changes in Australia's climate. In: Pearman GI (ed) Greenhouse: planning for climate change. CSIRO, Melbourne, p 35-51

Renwick JA, Katzfey JJ, Nguyen KC, McGregor JL (1998) Regional model simulations of New Zealand climate. J Geophys Res 103:5973-5982

Rotach MW, Marinucci MR, Wild M, Tschuck P, Ohmura A, Beniston M (1997) Nested regional simulation of climate change over the Alps for the scenario of a doubled greenhouse forcing. Theor Appl Clim 57:209-227

Rotmans J, Hulme M, Downing TE (1994) Climate change implications for Europe: an application of the ESCAPE model. Global Environ Change 4:97-124

Schreider SY, Jakeman AJ, Whetton PH, Pittock AB (1997) Estimation of climate impact on water availability and extreme events for snow-free and snow-affected catchments of the Murray-Darling Basin. Aust J Water Resour 2: $35-46$

Sutherst RW, Maywald GF, Skarratt DB (1995) Predicting insect distributions in a changed climate. In: Harrington R, Stork NE (eds) Insects in a changing environment. Academic Press, London, p 59-91

von Storch H, Zorita E, Cubasch U (1993) Downscaling of global climate change estimates to regional scales: an application of the Iberian rainfall in wintertime. J Clim 6: $1161-1171$

Walsh KJE, McGregor JL (1995) January and July climate simulations over the Australian region using a limitedarea model. J Clim 8:2387-2403

Wang QJ, Nathan RJ, Moran RJ, James B (1999) Impact of climate changes on the security of the water supply of the Campaspe System. In: Proceedings of the 25th Hydrology and Water Resources Symposium, Brisbane. Institution of Engineers, Canberra, p 135-40

Watterson IG, O'Farrell SP, Dix MR (1997) Energy transport in climates simulated by a GCM which includes dynamic sea ice. J Geophys Res 102:11027-11037

Whetton PH (1986) A synoptic climatological analysis of Victorian rainfall variability. $\mathrm{PhD}$ thesis, Department of Meteorology, University of Melbourne

Editorial responsibility: Mike Hulme, Norwich, United Kingdom
Whetton PH (1988) A synoptic climatological analysis of rainfall variability in southeastern Australia. J Climatol 8: 155-177

Whetton PH, Pittock AB (1990) Regional impact of the enhanced greenhouse effect on Victoria: annual research report 1990. CSIRO Division of Atmospheric Research and EPA Victoria, Victorian Government, Melbourne

Whetton PH, Rayner PJ, Pittock AB, Haylock MR (1994) An assessment of possible climate change in the Australian region based on an intercomparison of general circulation modeling results. J Clim 7:441-463

Whetton PH, Haylock MR, Galloway R (1996a) Climate change and snow-cover duration in the Australian Alps. Clim Change 32:447-479

Whetton PH, England MH, O'Farrell SP, Watterson IG, Pittock AB (1996b) Global comparison of the regional rainfall results of enhanced greenhouse coupled and mixed layer ocean experiments: implications for climate change scenario development. Clim Change 33:497-519

Whetton PH, Pittock AB, Labraga JC, Mullan AB, Joubert AM (1996c) Climate change: developing southern hemisphere perspectives. In: Giambelluca TW, Henderson-Sellers A (eds) Research and developments in climate and climatology. Wiley, Chichester, p 89-130

Whetton PH, Katzfey JJ, Nguyen KC, McGregor JL, Hennessy KJ (1997) Fine resolution climate change scenarios for New South Wales. Part 2: Climatic variability. NSW Environment Protection Authority, Chatswood, NSW

Whetton PH, Hennessy KJ, Wu X, McGregor JL, Katzfey JJ, Nguyen KC (2000a) Fine resolution assessment of enhanced greenhouse climate change in Victoria: climate averages based on a doubled $\mathrm{CO}_{2}$ simulation. CSIRO and Victorian Department of Natural Resources and Environment, Melbourne

Whetton PH, Katzfey JJ, Nguyen KC, McGregor JL, Page CM, Elliot TI, Hennessy KJ (2000b) Fine resolution assessment of enhanced greenhouse climate change in Victoria: climate averages and variability based on a doubled $\mathrm{CO}_{2}$ simulation. CSIRO and Victorian Department of Natural Resources and Environment, Melbourne

Wilby RL, Wigley TML (1997) Downscaling general circulation model output: a review of methods and limitations. Prog Phys Geogr 21:530-548

Submitted: July 7, 1999; Accepted: July 27, 2000

Proofs received from author(s): October 30, 2000 